\title{
Making Carbon-Emission Reduction Decisions in Supply Chains Based on Vertical Spillover and Environmental Awareness of Consumers
}

\author{
Guilan Han \\ Management School of Jinan University, Guangzhou, China \\ Email: 15622761549@163.com
}

How to cite this paper: Han, G.L. (2019) Making Carbon-Emission Reduction Decisions in Supply Chains Based on Vertical Spillover and Environmental Awareness of Consumers. Open Journal of Business and Management, 7, 1657-1689.

https://doi.org/10.4236/ojbm.2019.74116

Received: June 20, 2019

Accepted: September 14, 2019

Published: September 17, 2019

Copyright (c) 2019 by author(s) and Scientific Research Publishing Inc. This work is licensed under the Creative Commons Attribution International License (CC BY 4.0).

http://creativecommons.org/licenses/by/4.0/

\begin{abstract}
As the environmental awareness of consumers continues to improve and vertical spillover between up-stream and down-stream enterprises is occurring more and more frequently, firms have to consider the two factors when reducing the emissions. To investigate the influence of vertical spillover and environmental awareness of consumers on the decision-making process and profits realized by the supply chain, a simple two-stage supply chain is established (consisting of one supplier and one manufacturer). Centralized and decentralized decision-making models are compared. In the case of centralized, we find that the manufacturer puts in a greater effort to reduce emissions compared to the supplier. With decentralized decision making, the emission-reduction efforts of both parties depend on the vertical spillover rates and environmental awareness levels of the consumers. As the vertical spillover rates and environmental awareness of consumers improve, the differences in emission-reduction effort and profits in the supply chain under the two decision-making models become larger. Furthermore, the coordination efficiency in the supply chain is lower. The problem of coordination in the supply chain is further investigated using a Nash bargaining model. We find that there is an optimal profit distribution ratio which enables the supply chain to be coordinated.
\end{abstract}

\section{Keywords}

Sustainable Supply Chain, Supply Chain Coordination, Game Theory, Vertical Spillover, Carbon-Emission Reduction, Nash Bargaining

\section{Introduction}

The emission of greenhouse gases causes global warming. This is an undeniable 
fact that has attracted the attention of the majority of countries around the world. To develop some coordination between economic and environmental concerns, many countries have made various efforts to tackle the problem of greenhouse emissions, from the signing of the Kyoto Protocol in 1997, to the holding of the World Climate Conference in Paris in 2015 [1] [2] [3]. The European carbon-emission trade system built in 2005 has made a great contribution to reducing global carbon emissions. It achieved this by peremptorily stipulating the carbon emission of enterprises and imposing market regulations [4]. Several countries, e.g. Canada and Australia, control the carbon emission of enterprises by imposing carbon taxes [5]. In September 2015, the Chinese president, Xi Jinping, affirmed in Sino-US Joint Declaration on Climate Changes that a national carbon-emission trade system would start in 2017. The aim is that by 2030 the $\mathrm{CO}_{2}$ emission per unit GDP will be 60\% - 65\% lower than that in 2005 .

Apart from gaining the attention of governments, the environmental awareness of consumers is also constantly improving. An investigation of potential buyers of automobiles in Germany leads to the conclusion that the carbon-emission level of the automobile has an important effect on their decision to purchase an automobile or not [6]. Additionally, the number of consumers with an environmental awareness is growing increasingly. In 2005, for example, the proportion of the European population that was willing to purchase expensive, environmentally-friendly products was $31 \%$. This rose to $75 \%$ in 2008 [7]. The environmental awareness of consumers has been an important factor influencing willingness-to-pay.

Under pressure from both governments and consumers, enterprises have had to pay more attention to environmental issues. For example, Dell (one of the biggest manufacturers in the world) planned to have their carbon emissions decrease by $40 \%$ in 2015 compared to those in 2007. To achieve the goal, Dell strengthened the cooperation with their suppliers and, by $2009,80 \%$ of the suppliers satisfied the environmental requirements of Dell and participated in a carbon-disclosure project [8]. Similarly, to improve generating efficiency and reduce pollution in the coal power industry, power plants now place certain requirements on their coal supplies (e.g. ash content, cohesiveness, and coke ability). Subsequently, coal companies process the as-mined raw coal according to the requirements stipulated. In this context, coal enterprises and power plants tend to share some of their information about technology improvements and other statistical data. Therefore, numerous enterprises are striving for carbon-emission reduction and are willing to unite with suppliers to achieve a favorable effect on emission reduction.

\section{Problem Description}

According to the foregoing discussion, the primary factors influencing emission-reduction decision making in a supply chain are:

1) The environmental awareness of the consumers. The node enterprises in a supply chain have been forced to positively reduce carbon emissions by various 
government regulations including: carbon limits [9], carbon taxes [10], and carbon trade schemes [11]. In addition, people are attaching more importance to environmental problems. Thus, the improving low-carbon (LC) awareness of consumers is another important reason why enterprises are becoming more willing to reduce carbon emissions. Therefore, the influence of the environmental awareness of consumers on demand is investigated as an important factor [8] [12].

2) Vertical spillover. This refers to the "spillover" effect between the up-stream and down-stream enterprises in a supply chain. To be more specific, it refers to the situation wherein when any of the up-stream and down-stream enterprises in a supply chain are engaged in an activity and are influenced not just by the prospective effect but also by the indirect effect of other members in the supply chain simultaneously [13]. As already mentioned, in order to realize a favorable effect, numerous manufacturers cooperate with their suppliers to synchronously reduce carbon emissions. In the process, there is spillover in terms of knowledge and technology caused by information sharing and cooperative R\&D by the down-stream manufacturers to promote green and emission-reducing technology in the up-stream suppliers. Moreover, the supply of green materials and parts by up-stream suppliers improves the carbon-emission levels of the down-stream manufacturers. Therefore, the carbon-emission reduction efforts in a supply chain (such as R\&D of green and emission-reduction technologies) by the up-stream and down-stream enterprises in terms of emission reduction exhibit positive externality, namely, a vertical spillover effect. On this basis, vertical spillover is regarded as another research focus.

According to the above discussion, the following problems need addressing:

1) What is the effect of the consumers' environmental awareness on carbon-emission reduction and profits in a supply chain?

2) How does the vertical spillover of the up-stream and down-stream enterprises affect the emission-reduction decision-making process and coordination efficiency in a supply chain?

3) How do the members of a supply chain deal with each other to prevent their own profits from decreasing? And what are the roles played by vertical spillover and environmental awareness?

To answer these questions, a two-stage supply chain consisting of a supplier and a manufacturer is first established. The two enterprises monitor their carbon emissions during production and strive for emission reduction under the carbon taxes imposed by governments and LC demand of consumers. If the decision-making process is decentralized, the dynamic game order of the two enterprises is arranged as follows. The supplier first determines their level of effort required for emission reduction and the wholesale price. Then, the manufacturer determines their emission-reduction effort level and the retail price.

To make the analysis more convenient, we first consider a centralized decision-making model to use as a standard (that is the up-stream and down-stream 
enterprises do not take the maximization of their own profits as their objective but rather that of the whole supply chain). Secondly, the optimal effort levels and prices of the enterprises under the different decision-making processes are acquired using game theory. In addition, the influence of vertical spillover and environmental awareness of consumers on the emission-reduction decision-making process in the supply chain is analyzed. Finally, a Nash bargaining model is employed to coordinate the supply chain to achieve preferable carbon-emission reduction and improve the profits of the members of the supply chain.

The rest of this paper is arranged as follows. Section 3 gives a review of the relevant research in the literature of and Section 4 provides a description of the models and basic hypotheses. Section 5 presents an analysis of the models and main propositions. Section 6 summarizes the study and points out its innovative conclusions, deficiencies, and our future research intentions.

\section{Literature Review}

We review the existing literature in terms of three principal aspects: environmental awareness of consumers, vertical spillover, and cooperative game models.

Under the operating framework of a supply chain, an enterprise's decision making with respect to carbon-emission reduction is clearly influenced by the environmental awareness of its consumers. [14] investigated the market in Berlin, Germany, and found that improving environmental quality promoted demand. Moreover, the eagerness of consumers' to pay for environmentally-friendly products has driven numerous producers to apply environmental technologies. After studying the influence of consumers' environmental awareness on node enterprises in two competitive supply chains, [15] suggested that the two retailers and manufacturer can benefit as the environmental awareness of the consumers rises. For a manufacturer whose level of environmental protection is weak, profits are positively correlated with the consumers' environmental awareness when the competitiveness level in the supply chain is low. However, the former is negatively correlated with the latter when the competitiveness level is high. [16] established a two-stage supply chain composed of a manufacturer and a retailer and assumed that consumers have an LC preference. They analyzed emission-reduction effort levels and prices of LC products in the supply chain under centralized and decentralized decision-making scenarios. Finally, they discussed the influence of wholesale price, revenue sharing, and quantity discount contracts on the supply chain. In subsequent work, [17] found that manufacturers produce LC products when the preference of consumers for such products is larger than a certain threshold. Considering that carbon-emission reduction promotes demand, [18] proposed two approaches to emission reduction: the manufacturer pays expenses to the supplier or to a third party. It can be seen that whether the emission-reduction services of the third party exist or not, the transfer of payment from the manufacturer to the up-stream supplier is absolutely in favor of carbon-emission reduction and profit increase in the supply chain. Assuming that consumers are all environmentalists, [19] suggested that a 
cost-sharing contract associated with carbon-emission reduction is a Pareto improvement under the dominance of the retailer. However, the wholesale price contract cannot increase the profits of a supply chain unless the consumers have strong LC awareness. Both the wholesale price and cost sharing of carbon-emission reduction contracts are Pareto improvements when the retailer has the same status as the manufacturer. [20] established a two-stage LC supply chain composed of a manufacturer and a retailer which considered the promotion effect of advertisements on demand as well as the LC preferences of the consumers. They investigated the influence of advertisement cooperation and cost sharing of the advertisements and carbon emissions on the LC supply chain to further explore decision making and the coordination problem of supply chains when the retailer exhibits fairness preferences.

However, the existing research on carbon-emission reduction in a supply chain does not consider vertical spillover. In fact, when reducing carbon emissions in a supply chain, the effort ( $R \& D$ of green and emission-reducing technologies) expended by up-stream and down-stream enterprises to reduce emissions exhibits positive externality. Moreover, information sharing frequently occurs in addition to the vertical spillover of knowledge and technology between up-stream and down-stream enterprises. Thus, we ask: how does vertical spillover affect decision making with respect to carbon-emission reduction in the up-stream and down-stream enterprises of a supply chain? Obviously, studying this problem has important practical as well as theoretical value.

At present, there is an abundant amount of research on the effects of spillover, including horizontal spillover (within the same industry) and vertical spillover (between longitudinal industries). In relation to horizontal spillover, [21] establish a two-stage duopoly game model. Their results show that cooperation promotes technological innovation more favorably compared to competition when the horizontal spillover rate exceeds 0.5. Furthermore, there is a stronger degree of technological innovation if social welfare is taken as the target. By combining horizontal spillover with carbon-emission reduction, [22] investigated whether two Cournot competition enterprises cooperate to reduce carbon emissions when governments impose carbon taxes. They found that the emission-reduction effort of the two enterprises is greater when there is cooperation compared to when it is absent. [23] considered two different types of horizontal spillover (achievement and investment) and studied the problem of emission-reduction decision making by the two enterprises subject to different spillover effects. They revealed that there is a larger emission-reduction effort made for an investment spillover model, but the total carbon emission that occurs is larger.

After exploring the influence of vertical spillover between industries with respect to investment in R\&D and social welfare, [24] suggested that vertical spillover is more beneficial for increasing such investment compared to horizontal spillover. [25] constructed a duopoly model consisting of two suppliers and two manufacturers. The model was used to show that vertically cooperative R\&D can bring about better social welfare improvements than noncooperative $R \& D$ when 
the longitudinally cooperating enterprises can coordinate investment decision making and fully share their knowledge. By simultaneously considering horizontal and vertical spillover, [13] divided R\&D stages into four modes: noncooperation, horizontal, vertical, and mixed cooperation. The results indicate that when horizontal spillover is at a high level, horizontal cooperation increases $R \& D$ investment (and vice versa). However, the influence of vertical spillover and cooperation on R\&D investment was found to be uncertain.

The above research indicates that only a few studies have considered carbon-emission reduction from the perspective of horizontal spillover; none appears to consider the problem in terms of vertical spillover. In view of this, based on practical considerations, vertical spillover is introduced into the carbon-emission reduction problem in a supply chain. Thus, the influence of vertical spillover and environmental awareness of consumers on emission-reduction decision making and profits of the node enterprises in a supply chain is explored in this work. Additionally, coordination in the supply chain is also investigated to increase the efficiency of emission reduction and improve the profits of the node enterprises. A bargaining model is used to study how the up-stream and down-stream enterprises should distribute the obtained benefits during cooperative emission-reduction.

The bargaining model was first proposed by Nash [26] [27] and numerous scholars have since applied the model to study supply chains. For example, [28] considered two competitive supply chains. In their work, a manufacturer offers retailers wholesale prices or two-part tariff contracts as part of their contract-selection discussions. The retailers use the discussions to make decisions about what goods to order from the manufacturer. Different game models were considered (Steinberg and bargaining games). By assuming that demand is influenced by prices and promotional effort, [29] discussed three different negotiation schemes between manufacturers and retailers: wholesale prices, promotional effort levels, and a combination of the two. The results suggest that, irrespective of whether the supply chains are monopolistic or competitive, bargaining involving both wholesale price and promotional effort level is superior to negotiations involving just one factor. [30] established a duopoly competitive inverse supply chain composed of two manufacturers and two inverse suppliers and investigated the effect of the bargaining power of the manufacturers and suppliers on it. They demonstrated that if the two inverse suppliers are allied, then their bargaining power increases while the profits of the manufacturers decrease. Moreover, if the inverse suppliers play a dominant role in the market, their excessive bargaining power after alignment will probably cause the profits of all the members in the supply chain to fall. [8] investigated a green supply chain consisting of a single manufacturer and a single retailer. They assumed that the retailer provides a cost-sharing contract for the manufacturer and the sharing proportion is determined through negotiations. Subsequently, an equilibrium solution could be found and the sharing proportion determined. Additionally, this work verified that a Nash bargaining model can bring high green levels, as 
well as coordinating the supply chain. In contrast to the existing research, this model is used in this study to solve the carbon-emission reduction problem for a supply chain.

\section{Model Description and Hypotheses}

In order to investigate the carbon-emission reduction problem in a supply chain, a two-stage supply chain (composed of a supplier and a manufacturer) is established and discussed under centralized and decentralized decision-making conditions. The hypotheses and symbols we use are as follows:

1) The supplier has a marginal production cost of $c_{s}$ and sells the parts to the manufacturer at a wholesale price $w$. The manufacturer incurs a cost $c_{m}$ to produce the final products by using the parts and sells the products to consumers at a retail price $p$.

2) A unit of parts from the supplier can only be transformed into one unit of the final product by the manufacturer. This means that the up-stream and down-stream enterprises have the same yields and the market demand clears.

3) The carbon emissions from the two enterprises inevitably occur during production. The initial carbon-emission level of the supplier producing a unit of parts is $e_{s}$, while that of the manufacturer producing a unit of final product is $e_{m}$. To ensure generality, let $e_{s} \geq e_{m}>0$.

4) As in [18], the government synchronously imposes carbon taxes on the supplier and manufacturer in order to decrease carbon emission and protect the environment. The carbon tax $t(>0)$ is levied per unit carbon emission.

5) To relieve the tax burden, the up-stream and down-stream enterprises both strive for emission reduction. The emission-reduction effort levels of the supplier and manufacturer are $r_{s}$ and $r_{m}$, respectively. Due to the vertical spillover effect, the effective emission-reduction levels of the supplier and the manufacturer are $r_{s}+\beta_{s} r_{m}\left(\leq e_{s}\right)$ and $r_{m}+\beta_{m} r_{s}\left(\leq e_{m}\right)$, respectively. In these expressions, $\beta_{s}$ refers to the spillover rate of the supplier acquired from the manufacturer, while $\beta_{m}$ represents that of the manufacturer acquired from the supplier [25]. To ensure different spillover rates obtained by the up-stream and down-stream enterprises do not impact upon important results and conclusions, it is assumed that $\beta_{s}=\beta_{m}=\beta$ and $0 \leq \beta \leq 1$.

6) According to [21], the results depend quadratically on the effort level. Thus, we take the costs of the up-stream and down-stream enterprises with respect to carbon-emission reduction to be $z_{s} r_{s}^{2} / 2$ and $z_{m} r_{m}^{2} / 2$, respectively. To simplify the analysis, it is further assumed that $z_{s}=z_{m}=z$. To ensure that the models have equilibrium solutions, we also assume that $z$ of carbon emission reduction satisfies $z>\left[2 b k t(1+\beta)^{2}+k^{2}\left(1+\beta^{2}\right)+2 b^{2} t^{2}(1+\beta)^{2}\right] / 2 b$.

7) According to [15] and [19], consumers are more willing to purchase LC products. As the consumers purchase the final products from the manufacturer and understand the carbon footprint of the manufacturer, it is considered that the emission-reduction level of the manufacturer influences the demands of the consumers. The demand function $q$ can be expressed in the form: 


$$
q=a-b p+k\left(r_{m}+\beta r_{s}\right),
$$

where $a(>b p), b(>0)$, and $k(>0)$ refer to the potential market capacity, sensitivity coefficient of the consumers to prices, and the environmental awareness level of the consumers, respectively.

8) The total carbon-emission level of the whole supply chain is $E$ and $=e q$. Where, where

$$
e=\left[e_{s}-\left(r_{s}+\beta r_{m}\right)\right]+\left[e_{m}-\left(r_{m}+\beta r_{s}\right)\right]=\left(e_{m}+e_{s}\right)-(1+\beta)\left(r_{m}+r_{s}\right)
$$

refers to the carbon emission level of refers to the carbon-emission level per unit of products.

9) The profits of the up-stream and down-stream enterprises can be expressed in the form:

$$
\begin{gathered}
\pi_{s}=\left(w-c_{s}\right) q-t\left[e_{s}-\left(r_{s}+\beta r_{m}\right)\right] q-\frac{1}{2} z r_{s}^{2}, \\
\pi_{m}=\left(p-w-c_{m}\right) q-t\left[e_{m}-\left(r_{m}+\beta r_{s}\right)\right] q-\frac{1}{2} z r_{m}^{2},
\end{gathered}
$$

respectively. In each expression, the first, second, and third items correspond to the income of the enterprise, cost of carbon taxes, and emission-reduction costs, respectively.

\section{Model Analysis}

\subsection{Centralized Supply Chain Model}

Under centralized conditions, the supplier and manufacturer can be regarded as one enterprise and, in this context, maximizing the profit of the whole supply chain is considered to be the objective. According to the model analysis, the profit of the supply chain is:

$$
\begin{aligned}
\pi= & {\left[a-b p+k\left(r_{m}+\beta r_{s}\right)\right]\left[p-c_{m}-c_{s}-t\left(e_{m}+e_{s}\right)+t(1+\beta)\left(r_{m}+r_{s}\right)\right] } \\
& -\frac{1}{2} z\left(r_{m}^{2}+r_{s}^{2}\right)
\end{aligned}
$$

To derive values for $p, r_{m}$, and $r_{s}$ a, we take partial derivatives of the profit with respect to each quantity:

$$
\begin{aligned}
\frac{\partial \pi}{\partial p}=a-2 b p+b\left(c_{m}+c_{s}\right)+k\left(r_{m}+\beta r_{s}\right)+b t\left[e_{m}+e_{s}-(1+\beta)\left(r_{m}+r_{s}\right)\right] \\
\frac{\partial \pi}{\partial r_{m}}=k\left(p-c_{m}-c_{s}\right)-z r_{m}+t(1+\beta)\left[a-b p+k\left(r_{m}+\beta r_{s}\right)\right] \\
\quad-k t\left[e_{m}+e_{s}-(1+\beta)\left(r_{m}+r_{s}\right)\right] \\
\frac{\partial \pi}{\partial r_{s}}=k \beta\left(p-c_{m}-c_{s}\right)-z r_{s}+t(1+\beta)\left(a-b p+k r_{m}+k \beta r_{s}\right) \\
\quad-k t \beta\left[e_{m}+e_{s}-(1+\beta)\left(r_{m}+r_{s}\right)\right]
\end{aligned}
$$

The corresponding Hessian matrix is thus 


$$
H\left(p, r_{m}, r_{s}\right)=\left[\begin{array}{ccc}
-2 b & k-b t(1+\beta) & k \beta-b t(1+\beta) \\
k-b t(1+\beta) & 2 k t(1+\beta)-z & k t(1+\beta)^{2} \\
k \beta-b t(1+\beta) & k t(1+\beta)^{2} & 2 k t \beta(1+\beta)-z
\end{array}\right] .
$$

To ensure that the profit of the supply chain is a "concave" function of $p, r_{m}$, and $r_{s}$, it is necessary to satisfy the conditions $H_{1}<0, H_{2}>0$ and $H_{3}<0$. According to our assumptions that

$$
z>\left[2 b k t(1+\beta)^{2}+k^{2}\left(1+\beta^{2}\right)+2 b^{2} t^{2}(1+\beta)^{2}\right] / 2 b,
$$

$0 \leq \beta \leq 1$, and $k, b, t>0$, it can be shown that the first-order principal minors are $-2 b<0,2 k t(1+\beta)-z<0$, and $2 k t \beta(1+\beta)-z<0$, while the second-order principal minors are $2 b z-[k+b t(1+\beta)]^{2}>0,2 b z-[k \beta+b t(1+\beta)]^{2}>0$, and $z^{2}-2 k t z(1+\beta)^{2}-k^{2} t^{2}\left(1-\beta^{2}\right)^{2}>0$. Moreover, the third-order principal minor is $z\left[2 b k t(1+\beta)^{2}+k^{2}\left(1+\beta^{2}\right)+2 b^{2} t^{2}(1+\beta)^{2}-2 b z\right]<0$.

Setting Equations (1)-(3) equal to 0, allows the equilibrium solution under centralized conditions to be found. To do this, we simultaneously solve the resulting equations to yield,

$$
\begin{gathered}
p^{C^{*}=} \frac{a\left[z-k t(1+\beta)^{2}-2 b t^{2}(1+\beta)^{2}\right]+\left(c_{m}+c_{s}+t e_{m}+t e_{s}\right)\left[b z-b k t(1+\beta)^{2}-k^{2}\left(1+\beta^{2}\right)\right]}{2 b z-2 b k t(1+\beta)^{2}-k^{2}\left(1+\beta^{2}\right)-2 b^{2} t^{2}(1+\beta)^{2}} \\
r_{m}^{C^{*}}=\frac{[k+b t(1+\beta)]\left[a-b\left(c_{m}+c_{s}\right)-b t\left(e_{m}+e_{s}\right)\right]}{2 b z-2 b k t(1+\beta)^{2}-k^{2}\left(1+\beta^{2}\right)-2 b^{2} t^{2}(1+\beta)^{2}} \\
r_{s}^{C^{*}}=\frac{[k \beta+b t(1+\beta)]\left[a-b\left(c_{m}+c_{s}\right)-b t\left(e_{m}+e_{s}\right)\right]}{2 b z-2 b k t(1+\beta)^{2}-k^{2}\left(1+\beta^{2}\right)-2 b^{2} t^{2}(1+\beta)^{2}}
\end{gathered}
$$

The following equations can also be obtained:

$$
\begin{gathered}
q^{C^{*}}=\frac{b z\left[a-b\left(c_{m}+c_{s}\right)-b t\left(e_{m}+e_{s}\right)\right]}{2 b z-2 b k t(1+\beta)^{2}-k^{2}\left(1+\beta^{2}\right)-2 b^{2} t^{2}(1+\beta)^{2}}, \\
\pi^{C^{*}}=\frac{z\left[a-b\left(c_{m}+c_{s}\right)-b t\left(e_{m}+e_{s}\right)\right]^{2}}{2\left[2 b z-2 b k t(1+\beta)^{2}-k^{2}\left(1+\beta^{2}\right)-2 b^{2} t^{2}(1+\beta)^{2}\right]} .
\end{gathered}
$$

The total carbon-emission level of the whole supply chain can thus be expressed as:

$$
E^{C^{*}}=\frac{b z\left[a-b\left(c_{m}+c_{s}\right)-b t\left(e_{m}+e_{s}\right)\right]\left\{\left[2 b z-b k t(1+\beta)^{2}-k^{2}\left(1+\beta^{2}\right)\right]\left(e_{m}+e_{s}\right)-(k+2 b t)(1+\beta)^{2}\left[a-b\left(c_{m}+c_{s}\right)\right]\right\}}{\left[2 b z-2 b k t(1+\beta)^{2}-k^{2}\left(1+\beta^{2}\right)-2 b^{2} t^{2}(1+\beta)^{2}\right]^{2}}
$$

We next introduce the first of our propositions.

Proposition 1:

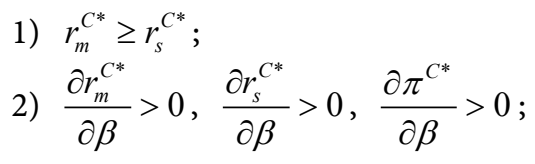


3) $\frac{\partial r_{m}^{C^{*}}}{\partial k}>0, \frac{\partial r_{s}^{C^{*}}}{\partial k}>0, \frac{\partial \pi^{C^{*}}}{\partial k}>0$.

The relations occurring in this proposition (between quantities appropriate to centralized decision-making conditions) are merely a mathematical expression of the following points:

1) The manufacturer's emission-reduction effort level is not lower than that of the supplier. This is mainly because the consumers are more familiar with the carbon footprint of the manufacturer. Although the supplier's emission-reduction effort level favors market demand, that of the manufacturer exerts a larger effect on the demand. In other words, the manufacturer has a "greater motivation" to make a stronger emission-reduction effort.

2) If the vertical spillover rate increases, the emission-reduction effort levels of the supplier and manufacturer, and the profits of the whole supply chain, will also rise. Vertical spillover has a positive effect on the carbon-emission reduction of up-stream and down-stream enterprises, so the supplier and manufacturer are more willing to make more effort to reduce emissions as the spillover rate grows. Although a rise in emission-reduction effort level promotes the cost of emission reduction, market demand also improves and this increases their incomes. In contrast, the profit of the whole supply chain still rises.

3) If the environmental awareness level of the consumers increases, the emission-reduction effort levels of the supplier and manufacturer, and the profit of the whole supply chain, will also rise. If the environmental awareness of consumers increases in strength, the supplier and manufacturer are likely to make more emission-reduction effort in order to obtain better market demand. Moreover, income rises as the market demand is constantly amplified and the increase in emission-reduction costs is offset. Thus, the profit of the whole supply chain grows.

\subsection{Decentralized Supply Chain Model}

Under decentralized conditions, the supplier and manufacturer make their decisions independently so as to maximize their own profits. The game order is as follows: 1) in the first stage, the supplier determines the price of the parts $w$ and the effort level $r_{s}$ for emission reduction; 2) in the second stage, the manufacturer determines the price of the final products $p$ and the effort level $r_{m}$ for emission reduction.

According to the converse solution principle, the values of $p$ and $r_{m}$ can be derived based on the profit of the manufacturer at the second stage:

$$
\begin{aligned}
& \frac{\partial \pi_{m}}{\partial p}=a-2 b p+b w+b c_{m}+b t e_{m}+k r_{m}-b t r_{m}+k \beta r_{s}-b t \beta r_{s}, \\
& \frac{\partial \pi_{m}}{\partial r_{m}}=k p+a t-b p t-k w-k c_{m}-k t e_{m}+2 k t r_{m}-z r_{m}+2 k t \beta r_{s} .
\end{aligned}
$$

The Hessian matrix is now $H\left(p, r_{m}\right)=\left[\begin{array}{cc}-2 b & k-b t \\ k-b t & 2 k t-z\end{array}\right]$; Once again, we use 
the inequalities $z>\left[2 b k t(1+\beta)^{2}+k^{2}\left(1+\beta^{2}\right)+2 b^{2} t^{2}(1+\beta)^{2}\right] / 2 b$ and $k, b, t>0$, to find that the first-order principal minors $(-2 b<0$ and $2 k t-z<0$ while the) and second-order principal minor $\left(2 b z-(k+b t)^{2}>0\right.$.). Thus, the profit of the manufacturer can be expressed as a concave function of $p$ and $r_{m}$.

Assuming that Equation (4) and Equation (5) can be set equal to 0 (equilibrium solution), the following values can be obtained by solving the resulting simultaneous equations:

$$
\begin{gathered}
p^{D}=\frac{a\left(z-k t+b t^{2}\right)+\left(w+c_{m}+t e_{m}\right)\left(b z-k^{2}-b k t\right)+(k-b t) z \beta r_{s}}{2 b z-(k+b t)^{2}}, \\
r_{m}^{D}=\frac{(k+b t)\left(a-b w-b c_{m}-b t e_{m}+k \beta r_{s}+b t \beta r_{s}\right)}{2 b z-(k+b t)^{2}} .
\end{gathered}
$$

After substituting $p^{D}$ and $r_{m}^{D}$ into the profit function of the supplier, the values of $w$ and $r_{s}$ can be derived in the first stage and the corresponding Hessian matrix elucidated:

$H\left(w, r_{s}\right)$

$$
=\left[\begin{array}{cc}
-\frac{2 b^{2} z\left[2 b z-k^{2}-b k t(2+\beta)-b^{2} t^{2}(1+\beta)\right]}{\left[2 b z-(k+b t)^{2}\right]^{2}} & -\frac{b z\left\{\left[2 b z-(k+b t)^{2}\right][b t-\beta(k+b t)]+2 b t \beta^{2}(k+b t)^{2}\right\}}{\left[2 b z-(k+b t)^{2}\right]^{2}} \\
-\frac{b z\left\{\left[2 b z-(k+b t)^{2}\right][b t-\beta(k+b t)]+2 b t \beta^{2}(k+b t)^{2}\right\}}{\left[2 b z-(k+b t)^{2}\right]^{2}} & \frac{2 z b t \beta(k+b t)\left[2 b z-(k+b t)^{2}\left(1-\beta^{2}\right)\right]}{\left[2 b z-(k+b t)^{2}\right]^{2}}-z
\end{array}\right] .
$$

As $\quad z>\left[2 b k t(1+\beta)^{2}+k^{2}\left(1+\beta^{2}\right)+2 b^{2} t^{2}(1+\beta)^{2}\right] / 2 b, \quad 0 \leq \beta \leq 1, \quad$ and $k, b, t>0$, the first-order principal minors

$$
-\left\{2 b^{2} z\left[2 b z-k^{2}-b k t(2+\beta)-b^{2} t^{2}(1+\beta)\right]\right\} /\left\{\left[2 b z-(k+b t)^{2}\right]^{2}\right\}<0
$$

and

$$
\left\{2 z b t \beta(k+b t)\left[2 b z-(k+b t)^{2}\left(1-\beta^{2}\right)\right]\right\} /\left\{\left[2 b z-(k+b t)^{2}\right]^{2}\right\}-z<0,
$$

and the second-order principal minor

$$
\begin{aligned}
& \left\{b^{2} z^{2}\left[4 b z-k^{2}\left(2+\beta^{2}\right)-2 b k t\left(2+2 \beta+\beta^{2}\right)-b^{2} t^{2}\left(3+4 \beta+\beta^{2}\right)\right]\right\} /\left\{\left[2 b z-(k+b t)^{2}\right]^{2}\right\}>0 \\
& w^{D^{*}}=\frac{\left(a-b c_{m}-b t e_{m}\right)\left[2 b z-k^{2}-b t(k+b t)(2+3 \beta)\right]+b\left(c_{s}+t e_{s}\right)\left[2 b z-\left(1+\beta^{2}\right)(k+b t)^{2}-b t \beta(k+b t)\right]}{4 b z-k^{2}\left(2+\beta^{2}\right)-2 b k t\left(2+2 \beta+\beta^{2}\right)-b^{2} t^{2}\left(3+4 \beta+\beta^{2}\right)}, \\
& r_{s}^{D^{*}}=\frac{[k \beta+b t(1+\beta)]\left(a-b c_{m}-b c_{s}-b t e_{m}-b t e_{s}\right)}{4 b z-k^{2}\left(2+\beta^{2}\right)-2 b k t\left(2+2 \beta+\beta^{2}\right)-b^{2} t^{2}\left(3+4 \beta+\beta^{2}\right)} .
\end{aligned}
$$


By inversely substituting the equilibrium solution into the second stage, the following equations can then be obtained

$$
\begin{gathered}
p^{D^{*}}=\frac{\left[3 b z-k^{2}-b k t\left(3+3 \beta+\beta^{2}\right)-b^{2} t^{2}\left(3+4 \beta+\beta^{2}\right)\right] a+b\left[c_{m}+c_{s}+t\left(e_{m}+e_{s}\right)\right]\left[b z-k^{2}\left(1+\beta^{2}\right)-b k t\left(1+\beta+\beta^{2}\right)\right]}{4 b z-k^{2}\left(2+\beta^{2}\right)-2 b k t\left(2+2 \beta+\beta^{2}\right)-b^{2} t^{2}\left(3+4 \beta+\beta^{2}\right)}, \\
r_{m}^{D^{*}}=\frac{(k+b t)\left(a-b c_{m}-b c_{s}-b t e_{m}-b t e_{s}\right)}{4 b z-k^{2}\left(2+\beta^{2}\right)-2 b k t\left(2+2 \beta+\beta^{2}\right)-b^{2} t^{2}\left(3+4 \beta+\beta^{2}\right)} .
\end{gathered}
$$

Furthermore, the equilibrium profits of the supplier, manufacturer, and supply chain can be expressed as:

$$
\begin{gathered}
\pi_{s}^{D^{*}}=\frac{z\left[a-b\left(c_{m}+c_{s}\right)-b t\left(e_{m}+e_{s}\right)\right]^{2}}{2\left[4 b z-k^{2}\left(2+\beta^{2}\right)-2 b k t\left(2+2 \beta+\beta^{2}\right)-b^{2} t^{2}\left(3+4 \beta+\beta^{2}\right)\right]}, \\
\pi_{m}^{D^{*}}=\frac{z\left[2 b z-(k+b t)^{2}\right]\left[a-b\left(c_{m}+c_{s}\right)-b t\left(e_{m}+e_{s}\right)\right]^{2}}{2\left[4 b z-k^{2}\left(2+\beta^{2}\right)-2 b k t\left(2+2 \beta+\beta^{2}\right)-b^{2} t^{2}\left(3+4 \beta+\beta^{2}\right)\right]^{2}}, \\
\pi^{D^{*}}=\frac{z\left[6 b z-k^{2}\left(3+\beta^{2}\right)-2 b k t\left(3+2 \beta+\beta^{2}\right)-b^{2} t^{2}(2+\beta)^{2}\right]\left[a-b\left(c_{m}+c_{s}\right)-b t\left(e_{m}+e_{s}\right)\right]^{2}}{2\left[4 b z-k^{2}\left(2+\beta^{2}\right)-2 b k t\left(2+2 \beta+\beta^{2}\right)-b^{2} t^{2}\left(3+4 \beta+\beta^{2}\right)\right]^{2}} .
\end{gathered}
$$

The total carbon-emission level of the whole supply chain can be expressed as:

$$
\begin{aligned}
E^{D^{*}}= & \frac{b z\left[a-b\left(c_{m}+c_{s}\right)-b t\left(e_{m}+e_{s}\right)\right]}{\left[4 b z-k^{2}\left(2+\beta^{2}\right)-2 b k t\left(2+2 \beta+\beta^{2}\right)-b^{2} t^{2}\left(3+4 \beta+\beta^{2}\right)\right]^{2}} \\
& \times\left\{\left[4 b z-k^{2}\left(2+\beta^{2}\right)-b k t\left(3+2 \beta+\beta^{2}\right)-b^{2} t^{2}(1+\beta)\right]\left(e_{m}+e_{s}\right)-(1+\beta)[k(1+\beta)+b t(2+\beta)]\left[a-b\left(c_{m}+c_{s}\right)\right]\right\} .
\end{aligned}
$$

\section{Proposition 2:}

1) When $\beta=1$, we have $r_{s}^{D^{*}}>r_{m}^{D^{*}}$; and when $\beta=0$, we have $r_{s}^{D^{*}}<r_{m}^{D^{*}}$; on the precondition of $0<\beta<1, r_{s}^{D^{*}}>r_{m}^{D^{*}}$ if $k<b t \beta /(1-\beta)$ and $r_{s}^{D^{*}} \leq r_{m}^{D^{*}}$ if $k \geq b t \beta /(1-\beta)$.

2) $\pi_{s}^{D^{*}}>\pi_{m}^{D^{*}}$.

Proposition 2 indicates that for the decentralized decision-making case:

1) When the up-stream and down-stream enterprises overflow fully $(\beta=1)$, the emission-reduction effort level of the supplier is higher than that of the manufacturer. On the other hand, the reverse is true when the up-stream and down-stream enterprises do not overflow ( $\beta=0$ ). When there is some overflow $(0<\beta<1)$, the supplier (manufacturer) exhibits a higher effort level if the environmental awareness level of the consumers is at a low (high) level.

When the up-stream and down-stream enterprises completely overflow, the influence of the supplier on market demand is the same as that of the manufacturer. However, the manufacturer benefits from late-mover advantage and decreases the cost of emission reduction by free-riding. Therefore, compared to the supplier, the manufacturer has a lower emission-reduction effort level. In contrast, when the up-stream and down-stream enterprises do not overflow, market demand is only influenced by the emission-reduction effort of the manufacturer. 
Thus, the manufacturer makes a high level of effort in order to obtain a large market share.

In the general case where there is some overflow between the up-stream and down-stream enterprises, the manufacturer will prefer to decrease the cost of emission reduction by free-riding when the environmental awareness of the consumers is low. However, when consumers have high environmental awareness, the manufacturer will prefer to acquire more market share by improving their emission-reduction effort level.

2) Due to the first-mover advantage of the supplier, the profit of the supplier is larger than that of the manufacturer.

Proposition 3:

1) $\frac{\partial r_{s}^{D^{*}}}{\partial \beta}>0, \frac{\partial r_{m}^{D^{*}}}{\partial \beta}>0, \frac{\partial \pi_{s}^{D^{*}}}{\partial \beta}>0, \frac{\partial \pi_{m}^{D^{*}}}{\partial \beta}>0 ;$
2) $\frac{\partial r_{s}^{D^{*}}}{\partial k}>0, \frac{\partial r_{m}^{D^{*}}}{\partial k}>0, \frac{\partial \pi_{s}^{D^{*}}}{\partial k}>0, \frac{\partial \pi_{m}^{D^{*}}}{\partial k}>0$.

This proposition implies that for decentralized decision making, the emission-reduction effort levels and profits of both the supplier and manufacturer grow when the spillover rates and environmental awareness level of the consumers increase.

This indicates that the vertical spillover rate and environmental awareness level of the consumers favor a reduction in pollution and improvement in profit. Therefore, the up-stream and down-stream enterprises in the supply chain are supposed to share information and increase their knowledge and technology spillovers so as to improve the vertical spillover rate. Moreover, it is necessary that they highlight the importance of environmental protection, widely carry out environmentally-friendly practices, and improve the environmental awareness levels of consumers.

\section{Proposition 4:}

Comparing carbon emission under centralized and decentralized decision-making conditions we have:

1) $e^{C^{*}}<e^{D^{*}}$

2) When the conditions are such that $b t^{2}(1+\beta)^{2}<z<z_{3}$, we have $E^{C^{*}}<E^{D^{*}}$; while $z>z_{3}$ corresponds to $E^{C^{*}}>E^{D^{*}}$. Here, $z_{3}$ refers to the root of the function $F(z)$ and; (which is cubic with respect to $z$ ) such that $z_{3} \in\left(k t(1+\beta)^{2}+k^{2}\left(1+\beta^{2}\right) / 2 b+\mathrm{b} t^{2}(1+\beta)^{2},+\infty\right)$, where:

$$
\begin{aligned}
F(z)= & {\left[2 b z-2 b t(k+b t)(1+\beta)^{2}-k^{2}\left(1+\beta^{2}\right)\right]^{2} } \\
& \times\left\{(1+\beta)[k(1+\beta)+b t(2+\beta)]\left(a-b c_{m}-b c_{s}\right)\right. \\
& \left.-\left[4 b z-k^{2}\left(2+\beta^{2}\right)-b k t\left(3+2 \beta+\beta^{2}\right)-b^{2} t^{2}(1+\beta)\right]\left(e_{m}+e_{s}\right)\right\} \\
& -\left[4 b z-k^{2}\left(2+\beta^{2}\right)-2 b k t\left(2+2 \beta+\beta^{2}\right)-b^{2} t^{2}\left(3+4 \beta+\beta^{2}\right)\right]^{2} \\
& \times\left\{(k+2 b t)(1+\beta)^{2}\left(a-b c_{m}-b c_{s}\right)-\left[2 b z-b k t(1+\beta)^{2}-k^{2}\left(1+\beta^{2}\right)\right]\left(e_{m}+e_{s}\right)\right\}
\end{aligned}
$$

This proposition illustrates that: 
1) The carbon-emission level per unit product in the centralized decision making case is lower than that in the decentralized case.

2) When the emission-reduction cost coefficient is at a low level, the total carbon emission in the centralized decision making case is lower than that in the decentralized case. This is because the quantity difference under centralized and decentralized conditions drops as the emission-reduction cost coefficients decrease $\left(\partial\left(q^{C^{*}}-q^{D^{*}}\right) / \partial z>0\right)$, while the difference in the carbon-emission levels per unit product increases $\left(\partial\left(e^{D^{*}}-e^{C^{*}}\right) / \partial z<0\right)$. Therefore, when the emission-reduction cost coefficient is at a low level, the quantity difference is small and the total carbon-emission value is mainly influenced by the carbon-emission level per unit product. This explains why the total carbon emission under centralized decision-making conditions is lower than that under decentralized conditions.

The total carbon emission is primarily influenced by the quantity when the emission-reduction cost coefficient is large. Thus, the total carbon emission under centralized decision making is larger than that under decentralized decision making.

\section{Proposition 5:}

Again comparing centralized and decentralized decision making cases, we also have:

1) $r_{s}^{C^{*}}>r_{s}^{D^{*}}, r_{m}^{C^{*}}>r_{m}^{D^{*}}, \pi^{C^{*}}>\pi^{D^{*}}$;

2) $\frac{\partial\left(r_{s}^{C^{*}}-r_{s}^{D^{*}}\right)}{\partial \beta}>0, \frac{\partial\left(r_{m}^{C^{*}}-r_{m}^{D^{*}}\right)}{\partial \beta}>0, \frac{\partial\left(\pi^{C^{*}}-\pi^{D^{*}}\right)}{\partial \beta}>0$;

3) $\frac{\partial\left(r_{s}^{C^{*}}-r_{s}^{D^{*}}\right)}{\partial k}>0, \frac{\partial\left(r_{m}^{C^{*}}-r_{m}^{D^{*}}\right)}{\partial k}>0, \frac{\partial\left(\pi^{C^{*}}-\pi^{D^{*}}\right)}{\partial k}>0$.

Proposition 5 indicates that:

1) The emission-reduction effort levels of the supplier and manufacturer and the profit of the supply chain in the centralized case are larger than those in the decentralized case.

2) With increasing vertical spillover rate, the difference in the emission-reduction effort levels of the supplier and manufacturer (as well as the profit of the whole supply chain) under centralized and decentralized decision-making conditions grows increasingly larger. That is, vertical spillover lowers the coordination efficiency $\mu=\pi^{D^{*}} / \pi^{C^{*}}$ of the supply chain. Therefore, it is particularly necessary to coordinate the supply chain if vertical spillover is operating.

3) With increasing environmental awareness of consumers, the difference in the emission-reduction effort levels of the supplier and manufacturer (as well as the profit of the supply chain) under centralized and decentralized decision-making conditions grows increasingly larger. Therefore, consistent with the effect of vertical spillover, environmental awareness also reduces the coordination efficiency of the supply chain.

\subsection{The Nash Bargaining Model}

It can be seen from the foregoing propositions that the profits in the centralized 
decision making case are higher than those in the decentralized case. However, it cannot be guaranteed that the members in the supply chain will always make decisions similar to those made in a centralized system. Only when the profit distribution satisfies the profit requirements of both enterprises will the cooperative relationship in the supply chain be able to reach a good state of coordination. By using a Nash bargaining game model, the coordination mechanism of the supply chain can be discussed under the assumption that the supplier and manufacturer negotiate a reasonable distribution ratio $\theta$ for the profit of the whole supply chain.

We assume that $\tau(0<\tau<1)$ refers to the bargaining ability of the supplier, so that the bargaining ability of the manufacturer is $1-\tau$; If the profit of the supplier is $\pi_{s}^{B}=(1-\theta) \pi^{C^{*}}$, then the profit of the manufacturer is $\pi_{m}^{B}=\theta \pi^{C^{*}}$. The coordination mechanism will only be accepted by the two parties when the Pareto improvement is performed on the supply chain, so it will inevitably satisfy $\pi_{s}^{B} \geq \pi_{s}^{D^{*}}$ and $\pi_{m}^{B} \geq \pi_{m}^{D^{*}}$. Guided by Nash [26] [27], the supplier and manufacturer jointly determine $\theta$ so that it maximizes the following objective function

$$
\begin{gathered}
\max _{\theta} f(\theta)=\left(\pi_{s}^{B}-\pi_{s}^{D^{*}}\right)^{\tau}\left(\pi_{m}^{B}-\pi_{m}^{D^{*}}\right)^{1-\tau} \\
\text { s.t. }\left\{\begin{array}{l}
0<\theta<1 \\
\pi_{s}^{B} \geq \pi_{s}^{D^{*}} \\
\pi_{m}^{B} \geq \pi_{m}^{D^{*}}
\end{array}\right.
\end{gathered}
$$

It can be shown that:

$$
\theta^{*}=\frac{(1-\tau)\left(\pi^{C^{*}}-\pi^{D^{*}}\right)+\pi_{m}^{D^{*}}}{\pi^{C^{*}}}
$$

Substituting the equilibrium profits into the above equation gives

$$
\theta^{*}=\frac{4(2-\tau) b^{2} z^{2}-M z+N}{\left[4 b z-k^{2}\left(2+\beta^{2}\right)-2 b k t\left(2+2 \beta+\beta^{2}\right)-b^{2} t^{2}\left(3+4 \beta+\beta^{2}\right)\right]^{2}}
$$

where,

$$
\begin{aligned}
M= & 2 b k^{2}\left(4+\beta^{2}-2 \tau\right)+4 b^{2} k t\left(4+2 \beta+\beta^{2}-2 \tau\right) \\
& +2 b^{3} t^{2}\left(5+4 \beta-2 \tau-\beta^{2}+3 \tau \beta^{2}\right),
\end{aligned}
$$

and

$$
\begin{aligned}
N= & k^{4}\left(2+\beta^{2}-\tau\right)+4 b k^{3} t\left(2+\beta+\beta^{2}-\tau\right) \\
& +b^{4} t^{4}(1+\beta)^{2}\left[3+2 \beta(\tau-1)+\beta^{2}(\tau-1)-\tau\right] \\
& +2 b^{3} k t^{3}(1+\beta)\left[5+\beta+\beta^{2}(\tau-1)+\beta^{3}(\tau-1)-2 \tau+2 \beta \tau\right] \\
& +b^{2} k^{2} t^{2}\left[13+12 \beta+\beta^{4}(\tau-1)-6 \tau+\beta^{2}(4+3 \tau)\right] .
\end{aligned}
$$

\section{Proposition 6:}

Comparing the bargaining model and decentralized model we have:

1) $0<\theta^{*}<1, \pi_{s}^{B^{*}}>\pi_{s}^{D^{*}}, \pi_{m}^{B^{*}}>\pi_{m}^{D^{*}}$; 
2) $\frac{\partial \pi_{s}^{B^{*}}}{\partial \beta}>0, \frac{\partial \pi_{m}^{B^{*}}}{\partial \beta}>0, \frac{\partial\left(\pi_{s}^{B^{*}}-\pi_{s}^{D^{*}}\right)}{\partial \beta}>0, \frac{\partial\left(\pi_{m}^{B^{*}}-\pi_{m}^{D^{*}}\right)}{\partial \beta}>0$;

3) $\frac{\partial \pi_{s}^{B^{*}}}{\partial k}>0, \frac{\partial \pi_{m}^{B^{*}}}{\partial k}>0, \frac{\partial\left(\pi_{s}^{B^{*}}-\pi_{s}^{D^{*}}\right)}{\partial k}>0, \frac{\partial\left(\pi_{m}^{B^{*}}-\pi_{m}^{D^{*}}\right)}{\partial k}>0$.

Proposition 6 illustrates that:

1) There exists an optimal distribution ratio that makes the profits of the supplier and manufacturer larger than those in the decentralized case. Additionally, as this optimal ratio exists, the two parties enjoy improved benefits and the supply chain becomes coordinated.

2) In the Nash bargaining model, the profits of the supplier and manufacturer increase with increasing spillover rate and the difference compared to the decentralized decision-making case grows increasingly. That is, vertical spillover improves the coordination efficiency of the supply chain under the bargaining mechanism.

3) The effect of the consumers' environmental awareness is consistent with that of the vertical spillover. That is, growth in environmental awareness promotes the profits of the supplier and manufacturer, and the profit difference between the two models also rises.

\section{Discussion}

The purpose of the study is to explore the effect of vertical spillover and environmental awareness of consumers on emission-reduction decision making and profits of up-stream and down-stream enterprises in a supply chain. To this end, we considered a monopolistic two-stage supply chain consisting of a single supplier and a single manufacturer each of which strive to reduce emissions in order to reduce their tax burdens and meet the demand for environmental protection from consumers. During emission reduction, they will probably exhibit a positive vertical spillover effect. The effect of vertical spillover and environmental awareness of consumers on the emission-reduction effort levels and profits of node enterprises, as well as the profit of the whole supply chain, is discussed in this work assuming both centralized or decentralized decision-making modes are involved. The two decision-making modes are compared using multiple indices, including the profit of the supply chain, emission-reduction effort levels, and total carbon-emission levels. Finally, in light of the problem of efficiency loss in the decentralized case, a bargaining model is introduced to coordinate the supply chain. Our conclusions are as follows:

1) In the centralized decision-making case, the emission-reduction effort level of the manufacturer is never smaller than that of the supplier. However, in the decentralized case, they have different effort levels depending on the situation: when the up-stream and down-stream enterprises fully overflow, the effort level of the supplier is greater than that of the manufacturer; when they do not overflow, the former is smaller than the latter. Moreover, if there is overflow, but it is not complete, the effort level of the sup-plier is greater than that of the 
manufacturer, if the consumers have low environmental awareness. Conversely, the former is lower than the latter when the environmental awareness of the consumers is great.

2) For both centralized and decentralized decision making, increasing the vertical spillover rate improves the emission-reduction effort levels and profits of the supplier and manufacturer. This implies that vertical spillover can reduce carbon emission and improve the profits of the enterprises. Therefore, it is essential that up-stream and down-stream enterprises in a supply chain share their information and increase knowledge and technology spillover so as to enhance the vertical spillover rate.

3) The carbon-emission level per unit product in the centralized decision-making case is lower than that in the decentralized case. However, the total carbon-emission level of the supply chain is not always less than that in the decentralized case and it needs to be discussed in the following contexts. When the emission-reduction cost coefficient is small, the total carbon-emission level in the centralized decision-making case is lower than that in the decentralized case. However, the former is higher than the latter when the cost coefficient is large.

4) The emission-reduction effort levels of the supplier and manufacturer and the profit of the whole supply chain in the centralized decision-making case are larger than those in the decentralized case. Moreover, with increasing vertical spillover, the effort levels of the supplier and manufacturer, as well as the profits of the supply chain, in the centralized decision-making case are increasingly different to those in the decentralized case. This shows that vertical spillover lowers the coordination efficiency in the supply chain. Therefore, if vertical spillover is present, it is especially necessary to coordinate the supply chain.

5) A bargaining model is able to coordinate the supply chain. We have found that there is an optimal profit distribution ratio that makes the profits of the supplier and manufacturer greater than those in the decentralized decision-making model. Moreover, the benefits of the two parties improve, and the profit difference between the two parties constantly grows, as the spillover rate increases. That is, vertical spillover improves the coordination efficiency of the supply chain in the bargaining model. Numerical analysis further shows that when the supplier has a favorable bargaining ability, the profit distribution ratio in the supply chain acquired by the manufacturer drops with increasing vertical spillover. However, the contrary behavior occurs with increasing vertical spill-over when the supplier has a poor bargaining ability.

\section{Conclusions and Recommendations}

We can know that there are many conclusions in this paper through the section six; following on from the above conclusions, the following advice is offered to those tasked with making decisions about emission-reduction in the up-stream and down-stream enterprises in a supply chain.

Firstly, a vertical spillover effect acts to improve the profits of the member en- 
terprises and supply chain. Thus, it is necessary for the members in the supply chain to communicate with each other, share information, and constantly strengthen their partnership so they can take full advantage of the benefits of the vertical spillover. They must not just consider their own benefits and damage the efficiency of the supply chain. Otherwise, not only will the emission-reduction efficiency decline, but also the profits of the supply chain will drop and they will not be able to acquire the optimal benefits available.

Secondly, increasing the environmental awareness of consumers favors reduced carbon emission and increased profit of the enterprises. Thus, the enterprises should create advertisements (public service advertising) that attract the attention of consumers. Additionally, enterprises can follow in the footsteps of Dell, i.e. disclose their carbon information so that consumers become more familiar with their product information. Also, enterprises should be encouraged to take part in environmental-awareness events (e.g. large-scale activities such as environmental and cultural festivals). This will motivate people to actively participate in creating a culture of environmental protection.

Finally, suppliers and manufacturers should be continually improving their manufacturing techniques to enhance the emission-reduction efficiency and lower their emission-reduction cost coefficients. By doing so, the pollution from the whole supply chain will decrease, which favors the creation of a satisfying industrial environment.

It must be said that there are certain deficiencies in the present study, some of which may dictate the direction of our future research. First, only a monopolic supply chain composed of one supplier and one manufacturer is investigated. Therefore, the effect of vertical spillover (and environmental awareness of consumers) on the emission-reduction strategies of competitive supply chains needs to be studied. In this context, it is not just the vertical spillover effect of up-stream and down-stream enterprises, but also the effect of the strength of the competition between sibling enterprises on the game results, which will have to be explored.

Secondly, for two competitive supply chains, horizontal spillover within the same industry needs to be studied as well as the vertical spillover among the longitudinal industries. In addition, emission-reduction decision making and profits can also be investigated when the node enterprises in the supply chains are simultaneously influenced by the two spillover effects.

Thirdly, considering that the government has a part to play in the game, the government could formulate its carbon taxation strategy by setting its objective to be the maximization of social welfare. On this basis, the node enterprises in the supply chain can then formulate their emission-reduction strategies according to these carbon taxes. Under such conditions, the changes that occur in the decision-making process in the supply chains need to be studied further.

\section{Conflicts of Interest}

The author declares no conflicts of interest regarding the publication of this paper. 


\section{References}

[1] Hubacek, K., Guan, D. and Barua, A. (2007) Changing Lifestyles and Consumption Patterns in Developing Countries: A Scenario Analysis for China and India. Futures, 39, 1084-1096. https://doi.org/10.1016/j.futures.2007.03.010

[2] Bilen, K., Ozyurt, O., Bakircik, et al. (2008) Energy Production, Consumption, and Environmental Pollution for Sustainable Development: A Case Study in Turkey. Renewable \& Sustainable Energy Reviews, 12, 1529-1561. https://doi.org/10.1016/j.rser.2007.03.003

[3] Blackman, A., Lahiri, B., Pizer, W., et al. (2010) Voluntary Environmental Regulation in Developing Countries: Mexico's Clean Industry Program. Journal of Environmental Economics and Management, 60, 182-192. https://doi.org/10.1016/j.jeem.2010.05.006

[4] Du, S.F., Hu, L. and Song, M.L. (2016) Production Optimization Considering Environmental Performance and Preference in the Cap-and-Trade System. Journal of Cleaner Production, 112, 1600-1607. https://doi.org/10.1016/j.jclepro.2014.08.086

[5] Wang, D.H., Wang, R.Y., Anderson, D.E., et al. (2015) Production Decision with Carbon Taxes and Green-Tech in a Duopoly Market. International Conference on Logistics, Informatics and Service Sciences, Barcelona, 27-29 July 2015, 1-6.

[6] Achtnicht, M. (2012) German Car Buyers' Willingness to Pay to Reduce $\mathrm{CO}_{2}$ Emissions. Climatic Change, 113, 679-697. https://doi.org/10.1007/s10584-011-0362-8

[7] Zhang, L.H., Wang, J.G. and You, J.X. (2015) Consumer Environmental Awareness and Channel Coordination with Two Substitutable Products. European Journal of Operational Research, 241, 63-73. https://doi.org/10.1016/j.ejor.2014.07.043

[8] Ghosh, D. and Shah, J. (2015) Supply Chain Analysis under Green Sensitive Consumer Demand and Cost Sharing Contract. International Journal of Production Economics, 164, 319-329. https://doi.org/10.1016/j.ijpe.2014.11.005

[9] Chen, X., Benjaafar, S. and Elomri, A. (2013) The Carbon-Constrained EOQ. Operations Research Letters, 41, 172-179. https://doi.org/10.1016/j.orl.2012.12.003

[10] Chen, X. and Hao, G. (2015) Sustainable Pricing and Production Policies for Two Competing Firms with Carbon Emissions Tax. International Journal of Production Research, 53, 6408-6420. https://doi.org/10.1080/00207543.2014.932928

[11] Xu, X.P., Zhang, W., He, P., et al. (2017) Production and Pricing Problems in Make-to-Order Supply Chain with Cap-and-Trade Regulation. Omega, 66, 248-257. https://doi.org/10.1016/j.omega.2015.08.006

[12] Ghosh, D. and Shah, J. (2012) A Comparative Analysis of Greening Policies across Supply Chain Structures. International Journal of Production Economics, 135, 568-583. https://doi.org/10.1016/j.ijpe.2011.05.027

[13] Atallah, G. (2002) Vertical R\&D Spillovers, Cooperation, Market Structure, and Innovation. Economics of Innovation and New Technology, 11, 179-209. https://doi.org/10.1080/10438590210903

[14] Moon, W., Florkowski, W.J., Brückner, B. and Schonhof, I. (2002) Willingness to Pay for Environmental Practices: Implications for Eco-Labeling. Land Economics, 78, 88-102. https://doi.org/10.2307/3146925

[15] Liu, Z.G., Anderson, T.D. and Cruz, J.M. (2012) Consumer Environmental Awareness and Competition in Two-Stage Supply Chains. European Journal of Operational Research, 218, 602-613. https://doi.org/10.1016/j.ejor.2011.11.027

[16] Du, S.F., Zhu, J.A., Jiao, H.F., et al. (2015) Game-Theoretical Analysis for Supply 
Chain with Consumer Preference to Low Carbon. International Journal of Production Research, 53, 3753-3768. https://doi.org/10.1080/00207543.2014.988888

[17] Du, S.F., Tang, W.Z. and Song, M.L. (2016) Low-Carbon Production with Low-Carbon Premium in Cap-and-Trade Regulation. Journal of Cleaner Production, 134, 652-662. https://doi.org/10.1016/j.jclepro.2016.01.012

[18] He, L.F., Zhao, D.Z. and Xia, L.J. (2015) Game Theoretic Analysis of Carbon Emission Abatement in Fashion Supply Chains Considering Vertical Incentives and Channel Structures. Sustainability, 7, 4280-4309. https://doi.org/10.3390/su7044280

[19] Wang, Q.P., Zhao, D.Z. and He, L.F. (2016) Contracting Emission Reduction for Supply Chains Considering Market Low-Carbon Preference. Journal of Cleaner Production, 120, 72-84. https://doi.org/10.1016/j.jclepro.2015.11.049

[20] Zhou, Y.J., Bao, M.J., Chen, X.L., et al. (2016) Co-Op Advertising and Emission Reduction Cost Sharing Contracts and Coordination in Low-Carbon Supply Chain Based on Fairness Concerns. Journal of Cleaner Production, 133, 402-413. https://doi.org/10.1016/j.jclepro.2016.05.097

[21] D’Aspremont, C. and Jacquemin, A. (1988) Cooperative and Noncooperative R\&D in Duopoly with Spillovers. The American Economic Review, 78, 1133-1137.

[22] Ouchida, Y. and Goto, D. (2016) Cournot Duopoly and Environmental R\&D under Regulator's Precommitment to an Emissions Tax. Applied Economics Letters, 23, 324-331. https://doi.org/10.1080/13504851.2015.1073831

[23] Mcdonald, S. and Poyago-Theotoky, J. (2016) Green Technology and Optimal Emissions Taxation. Journal of Public Economic Theory, 19, 362-376. https://doi.org/10.1111/jpet.12165

[24] Steurs, G. (1995) Inter-Industry R\&D Spillovers: What Difference Do They Make? International Journal of Industrial Organization, 13, 249-276. https://doi.org/10.1016/0167-7187(94)00455-b

[25] Ishii, A. (2004) Cooperative R\&D between Vertically Related Firms with Spillovers. International Journal of Industrial Organization, 22, 1213-1235. https://doi.org/10.1016/j.ijindorg.2004.05.003

[26] Nash, J.F. (1950) The Bargaining Problem. Econometrica, 18, 155-162. https://doi.org/10.2307/1907266

[27] Nash, J.F. (1953) Two-Person Cooperative Games. Econometrica, 21, 128-140. https://doi.org/10.2307/1906951

[28] Feng, Q. and Lu, L.X. (2013) Supply Chain Contracting under Competition: Bilateral Bargaining vs. Stackelberg. Production and Operations Management, 22, 661-675. https://doi.org/10.1111/j.1937-5956.2012.01417.x

[29] Wu, D.D. (2013) Bargaining in Supply Chain with Price and Promotional Effort Dependent Demand. Mathematical and Computer Modelling, 58, 1659-1669. https://doi.org/10.1016/j.mcm.2010.12.035

[30] Sheu, J.B. and Gao, X.Q. (2014) Alliance or No Alliance-Bargaining Power in Competing Reverse Supply Chains. European Journal of Operational Research, 233, 313-325. https://doi.org/10.1016/j.ejor.2013.09.021 


\section{Appendix}

\section{The proof of Proposition 1}

1) Due to

$$
q=a-b p+k\left(r_{m}+\beta r_{s}\right)=\frac{b z\left[a-b\left(c_{m}+c_{s}\right)-b t\left(e_{m}+e_{s}\right)\right]}{2 b z-2 b k t(1+\beta)^{2}-k^{2}\left(1+\beta^{2}\right)-2 b^{2} t^{2}(1+\beta)^{2}} .
$$

To make the demand greater than zero, it requires that

$$
\begin{aligned}
& a-b\left(c_{m}+c_{s}\right)-b t\left(e_{m}+e_{s}\right)>0, \\
& \text { and by } z>\frac{2 b k t(1+\beta)^{2}+k^{2}\left(1+\beta^{2}\right)+2 b^{2} t^{2}(1+\beta)^{2}}{2 b}, 0 \leq \beta \leq 1, k, b, t>0 \text {, we } \\
& \text { can get } r_{m}^{C^{*}}-r_{s}^{C^{*}}=\frac{k(1-\beta)\left[a-b\left(c_{m}+c_{s}\right)-b t\left(e_{m}+e_{s}\right)\right]}{2 b z-2 b k t(1+\beta)^{2}-k^{2}\left(1+\beta^{2}\right)-2 b^{2} t^{2}(1+\beta)^{2}} \geq 0 \text {, that is, } \\
& r_{m}^{C^{*}} \geq r_{s}^{C^{*}} \text {. Only if } \beta=1, r_{m}^{C^{*}}=r_{s}^{C^{*}} \text {. } \\
& \text { 2) Owing to } a-b\left(c_{m}+c_{s}\right)-b t\left(e_{m}+e_{s}\right)>0 \text {, } \\
& z>\frac{2 b k t(1+\beta)^{2}+k^{2}\left(1+\beta^{2}\right)+2 b^{2} t^{2}(1+\beta)^{2}}{2 b},
\end{aligned}
$$

To judge the size of $\frac{\partial r_{s}^{C^{*}}}{\partial \beta}$, we only compare $f(\beta)$ to 0 . Since

$$
f^{\prime}(\beta)=2 k^{3} \beta+4 b^{3} t^{3}(1+\beta)+b k^{2} t(2+6 \beta)+2 b k\left[2 b t^{2} \beta+2 b t^{2}(1+\beta)\right]>0,
$$

then $f(\beta)_{\min }=f(0)=2 b k z+2 b^{2} t z+2 b^{3} t^{3}-k^{3}-3 b k^{2} t$, owing to

$$
z>\frac{2 b k t(1+\beta)^{2}+k^{2}\left(1+\beta^{2}\right)+2 b^{2} t^{2}(1+\beta)^{2}}{2 b},
$$

$0 \leq \beta \leq 1$, and $k, b, t>0$, we get $f(0)>0$, thereby $\frac{\partial r_{s}^{C^{*}}}{\partial \beta}>0$.

Because $a-b\left(c_{m}+c_{s}\right)-b t\left(e_{m}+e_{s}\right)>0$,

$$
z>\frac{2 b k t(1+\beta)^{2}+k^{2}\left(1+\beta^{2}\right)+2 b^{2} t^{2}(1+\beta)^{2}}{2 b},
$$

$0 \leq \beta \leq 1$, and $k, b, t>0$, we get

$$
\frac{\partial \pi^{C^{*}}}{\partial \beta}=\frac{z\left[k^{2} \beta+2 b k t(1+\beta)+2 b^{2} t^{2}(1+\beta)\right]\left[a-b\left(c_{m}+c_{s}\right)-b t\left(e_{m}+e_{s}\right)\right]^{2}}{\left[2 b z-2 b k t(1+\beta)^{2}-k^{2}\left(1+\beta^{2}\right)-2 b^{2} t^{2}(1+\beta)^{2}\right]^{2}}>0 .
$$


3) Because $a-b\left(c_{m}+c_{s}\right)-b t\left(e_{m}+e_{s}\right)>0$,

$$
z>\frac{2 b k t(1+\beta)^{2}+k^{2}\left(1+\beta^{2}\right)+2 b^{2} t^{2}(1+\beta)^{2}}{2 b},
$$

$0 \leq \beta \leq 1$, and $k, b, t>0$, we get

$$
\begin{gathered}
\frac{\partial r_{m}^{C^{*}}}{\partial k}=\frac{\left[k^{2}\left(1+\beta^{2}\right)+2 b k t\left(1+\beta+\beta^{2}+\beta^{3}\right)+2 b z+2 b^{2} t^{2} \beta(1+\beta)^{2}\right]\left[a-b\left(c_{m}+c_{s}\right)-b t\left(e_{m}+e_{s}\right)\right]}{\left[2 b z-2 b k t(1+\beta)^{2}-k^{2}\left(1+\beta^{2}\right)-2 b^{2} t^{2}(1+\beta)^{2}\right]^{2}}>0, \\
\frac{\partial r_{s}^{C^{*}}}{\partial k}=\frac{\left[2 b^{2} t^{2}(1+\beta)^{2}+k^{2} \beta\left(1+\beta^{2}\right)+2 b z \beta+2 b k t\left(1+\beta+\beta^{2}+\beta^{3}\right)\right]\left[a-b\left(c_{m}+c_{s}\right)-b t\left(e_{m}+e_{s}\right)\right]}{\left[2 b z-2 b k t(1+\beta)^{2}-k^{2}\left(1+\beta^{2}\right)-2 b^{2} t^{2}(1+\beta)^{2}\right]^{2}}>0, \\
\text { and } \frac{\partial \pi^{C^{*}}}{\partial k}=\frac{z\left[b t(1+\beta)^{2}+k\left(1+\beta^{2}\right)\right]\left[a-b\left(c_{m}+c_{s}\right)-b t\left(e_{m}+e_{s}\right)\right]}{\left[2 b z-2 b k t(1+\beta)^{2}-k^{2}\left(1+\beta^{2}\right)-2 b^{2} t^{2}(1+\beta)^{2}\right]^{2}}>0 .
\end{gathered}
$$

\section{The proof of Proposition 2}

1) Owing to

$$
\begin{aligned}
& q=a-b p+k\left(r_{m}+\beta r_{s}\right)=\frac{b z\left[a-b\left(c_{m}+c_{s}\right)-b t\left(e_{m}+e_{s}\right)\right]}{4 b z-k^{2}\left(2+\beta^{2}\right)-2 b k t\left(2+2 \beta+\beta^{2}\right)-b^{2} t^{2}\left(3+4 \beta+\beta^{2}\right)}, \\
& \quad \text { and } z>\frac{2 b k t(1+\beta)^{2}+k^{2}\left(1+\beta^{2}\right)+2 b^{2} t^{2}(1+\beta)^{2}}{2 b}, \quad 0 \leq \beta \leq 1, \quad k, b, t>0 \text {. To }
\end{aligned}
$$

make the demand greater than zero, it requires that

$$
a-b\left(c_{m}+c_{s}\right)-b t\left(e_{m}+e_{s}\right)>0 .
$$

Because $\quad r_{s}^{D^{*}}-r_{m}^{D^{*}}=\frac{[b t \beta-k(1-\beta)]\left[a-b\left(c_{m}+c_{s}\right)-b t\left(e_{m}+e_{s}\right)\right]}{4 b z-k^{2}\left(2+\beta^{2}\right)-2 b k t\left(2+2 \beta+\beta^{2}\right)-b^{2} t^{2}\left(3+4 \beta+\beta^{2}\right)}$,

to determine the size of $r_{s}^{D^{*}}$ and $r_{m}^{D^{*}}$, only need compare bt $\beta-k(1-\beta)$ with 0 . Visibility, when $\beta=1, r_{s}^{D^{*}}>r_{m}^{D^{*}}$; when $\beta=0, r_{s}^{D^{*}}<r_{m}^{D^{*}}$; when $0<\beta<1$, if $k<\frac{b t \beta}{1-\beta}$, then $r_{s}^{D^{*}}>r_{m}^{D^{*}}$; if $k \geq \frac{b t \beta}{1-\beta}$, then $r_{s}^{D^{*}} \leq r_{m}^{D^{*}}$.

2)

$$
\begin{gathered}
\pi_{s}^{D^{*}}-\pi_{m}^{D^{*}}=\frac{z\left[2 b z-2 b k t(1+\beta)^{2}-k^{2}\left(1+\beta^{2}\right)-b^{2} t^{2}\left(2+4 \beta+\beta^{2}\right)\right]\left[a-b\left(c_{m}+c_{s}\right)-b t\left(e_{m}+e_{s}\right)\right]^{2}}{2\left[4 b z-k^{2}\left(2+\beta^{2}\right)-2 b k t\left(2+2 \beta+\beta^{2}\right)-b^{2} t^{2}\left(3+4 \beta+\beta^{2}\right)\right]^{2}} . \\
\text { By } z>\frac{2 b k t(1+\beta)^{2}+k^{2}\left(1+\beta^{2}\right)+2 b^{2} t^{2}(1+\beta)^{2}}{2 b}, 0 \leq \beta \leq 1 \text {, and } k, b, t>0 \text {, we } \\
\text { get } 2 b z-2 b k t(1+\beta)^{2}-k^{2}\left(1+\beta^{2}\right)-b^{2} t^{2}\left(2+4 \beta+\beta^{2}\right)>0 \text {, thus } \pi_{s}^{D^{*}}>\pi_{m}^{D^{*}} .
\end{gathered}
$$

The proof of Proposition 3

1) Since $a-b\left(c_{m}+c_{s}\right)-b t\left(e_{m}+e_{s}\right)>0$,

$$
z>\frac{2 b k t(1+\beta)^{2}+k^{2}\left(1+\beta^{2}\right)+2 b^{2} t^{2}(1+\beta)^{2}}{2 b},
$$




$$
\begin{aligned}
& 0 \leq \beta \leq 1, \quad k, b, t>0 \text {, then } \\
& \frac{\partial r_{s}^{D^{*}}}{\partial \beta}=\frac{(k+b t)\left[a-b\left(c_{m}+c_{s}\right)-b t\left(e_{m}+e_{s}\right)\right]\left\{\left[4 b z-4 b k t-2 k^{2}\right]+[k \beta+b t(1+\beta)]^{2}\right\}}{\left[4 b z-k^{2}\left(2+\beta^{2}\right)-2 b k t\left(2+2 \beta+\beta^{2}\right)-b^{2} t^{2}\left(3+4 \beta+\beta^{2}\right)\right]^{2}}>0, \\
& \frac{\partial r_{m}^{D^{*}}}{\partial \beta}=\frac{2(k+b t)^{2}[k \beta+b t(2+\beta)]\left[a-b\left(c_{m}+c_{s}\right)-b t\left(e_{m}+e_{s}\right)\right]}{\left[4 b z-k^{2}\left(2+\beta^{2}\right)-2 b k t\left(2+2 \beta+\beta^{2}\right)-b^{2} t^{2}\left(3+4 \beta+\beta^{2}\right)\right]^{2}}>0, \\
& \frac{\partial \pi_{s}^{D^{*}}}{\partial \beta}=\frac{z(k+b t)[k \beta+b t(2+\beta)]\left[a-b\left(c_{m}+c_{s}\right)-b t\left(e_{m}+e_{s}\right)\right]^{2}}{\left[4 b z-k^{2}\left(2+\beta^{2}\right)-2 b k t\left(2+2 \beta+\beta^{2}\right)-b^{2} t^{2}\left(3+4 \beta+\beta^{2}\right)\right]^{2}}>0, \\
& \frac{\partial \pi_{m}^{D^{*}}}{\partial \beta}=\frac{2 z(k+b t)[k \beta+b t(2+\beta)]\left[2 b z-(k+b t)^{2}\right]\left[a-b\left(c_{m}+c_{s}\right)-b t\left(e_{m}+e_{s}\right)\right]^{2}}{\left[4 b z-k^{2}\left(2+\beta^{2}\right)-2 b k t\left(2+2 \beta+\beta^{2}\right)-b^{2} t^{2}\left(3+4 \beta+\beta^{2}\right)\right]^{3}}>0 . \\
& z>\frac{2 b k t(1+\beta)^{2}+k^{2}\left(1+\beta^{2}\right)+2 b^{2} t^{2}(1+\beta)^{2}}{2 b},
\end{aligned}
$$

$0 \leq \beta \leq 1, k, b, t>0$, then we can get

$$
\begin{gathered}
\frac{\partial r_{s}^{D^{*}}}{\partial k}=\frac{\left[a-b\left(c_{m}+c_{s}\right)-b t\left(e_{m}+e_{s}\right)\right]\left[4 b z \beta+k^{2} \beta\left(2+\beta^{2}\right)+b^{2} t^{2}\left(4+5 \beta+2 \beta^{2}+\beta^{3}\right)+2 b k t\left(2+2 \beta+\beta^{2}+\beta^{3}\right)\right]}{\left[4 b z-k^{2}\left(2+\beta^{2}\right)-2 b k t\left(2+2 \beta+\beta^{2}\right)-b^{2} t^{2}\left(3+4 \beta+\beta^{2}\right)\right]^{2}}>0, \\
\frac{\partial r_{m}^{D^{*}}}{\partial k}=\frac{\left[a-b\left(c_{m}+c_{s}\right)-b t\left(e_{m}+e_{s}\right)\right]\left[4 b z+k^{2}\left(2+\beta^{2}\right)+2 b k t\left(2+\beta^{2}\right)+b^{2} t^{2}\left(1+\beta^{2}\right)\right]}{\left[4 b z-k^{2}\left(2+\beta^{2}\right)-2 b k t\left(2+2 \beta+\beta^{2}\right)-b^{2} t^{2}\left(3+4 \beta+\beta^{2}\right)\right]^{2}}>0, \\
\frac{\partial \pi_{s}^{D^{*}}}{\partial k}=\frac{z\left[k\left(2+\beta^{2}\right)+b t\left(2+2 \beta+\beta^{2}\right)\right]\left[a-b\left(c_{m}+c_{s}\right)-b t\left(e_{m}+e_{s}\right)\right]^{2}}{\left[4 b z-k^{2}\left(2+\beta^{2}\right)-2 b k t\left(2+2 \beta+\beta^{2}\right)-b^{2} t^{2}\left(3+4 \beta+\beta^{2}\right)\right]^{2}}>0, \\
\frac{\partial \pi_{m}^{D^{*}}}{\partial k}=\frac{z\left[a-b\left(c_{m}+c_{s}\right)-b t\left(e_{m}+e_{s}\right)\right]^{2} g(z)}{\left[4 b z-k^{2}\left(2+\beta^{2}\right)-2 b k t\left(2+2 \beta+\beta^{2}\right)-b^{2} t^{2}\left(3+4 \beta+\beta^{2}\right)\right]^{3}},
\end{gathered}
$$

where

$$
g(z)=\left[4 b^{2} t(1+\beta)^{2}+4 b k\left(1+\beta^{2}\right)\right] z-\left(1+\beta^{2}\right)(k+b t)^{3}-k(k+b t)(k+2 b t),
$$

it is obviously that we need compare $g(z)$ with 0 to determine the size of $\frac{\partial \pi_{m}^{D^{*}}}{\partial k}$. Because $g(z)$ is monotone increasing about $z$, and

$$
z>\frac{2 b k t(1+\beta)^{2}+k^{2}\left(1+\beta^{2}\right)+2 b^{2} t^{2}(1+\beta)^{2}}{2 b},
$$

$0 \leq \beta \leq 1, k, b, t>0$, then we have

$$
g(z)>g\left(\frac{2 b k t(1+\beta)^{2}+k^{2}\left(1+\beta^{2}\right)+2 b^{2} t^{2}(1+\beta)^{2}}{2 b}\right)
$$




$$
\begin{aligned}
= & k^{3} \beta^{2}\left(3+2 \beta^{2}\right)+3 b k^{2} t \beta\left(4+3 \beta+4 \beta^{2}+2 \beta^{3}\right) \\
& +b^{3} t^{3}\left(3+16 \beta+23 \beta^{2}+16 \beta^{3}+4 \beta^{4}\right) \\
& +b^{2} k t^{2}\left(3+24 \beta+29 \beta^{2}+24 \beta^{3}+8 \beta^{4}\right) \\
> & 0
\end{aligned}
$$

and sequentially $\frac{\partial \pi_{m}^{D^{*}}}{\partial k}>0$.

\section{The proof of Proposition 4}

1) Owing to $e=\left(e_{m}+e_{s}\right)-(1+\beta)\left(r_{m}+r_{s}\right)$, and by Proposition 5 we know $r_{s}^{C^{*}}>r_{s}^{D^{*}}, r_{m}^{C^{*}}>r_{m}^{D^{*}}$, thus $e^{C^{*}}<e^{D^{*}}$.

2)

$$
E^{C^{*}}-E^{D^{*}}=\frac{b z\left(a-b c_{m}-b c_{s}-b t e_{m}-b t e_{s}\right) F(z)}{\left[2 b z-2 b t(k+b t)(1+\beta)^{2}-k^{2}\left(1+\beta^{2}\right)\right]^{2}\left[4 b z-k^{2}\left(2+\beta^{2}\right)-2 b k t\left(2+2 \beta+\beta^{2}\right)-b^{2} t^{2}\left(3+4 \beta+\beta^{2}\right)\right]^{2}},
$$

where

$$
\begin{aligned}
F(z)= & {\left[2 b z-2 b t(k+b t)(1+\beta)^{2}-k^{2}\left(1+\beta^{2}\right)\right]^{2}\left\{(1+\beta)[k(1+\beta)+b t(2+\beta)]\left(a-b c_{m}-b c_{s}\right)\right.} \\
& \left.-\left[4 b z-k^{2}\left(2+\beta^{2}\right)-b k t\left(3+2 \beta+\beta^{2}\right)-b^{2} t^{2}(1+\beta)\right]\left(e_{m}+e_{s}\right)\right\} \\
& -\left[4 b z-k^{2}\left(2+\beta^{2}\right)-2 b k t\left(2+2 \beta+\beta^{2}\right)-b^{2} t^{2}\left(3+4 \beta+\beta^{2}\right)\right]^{2} \\
& \times\left\{(k+2 b t)(1+\beta)^{2}\left(a-b c_{m}-b c_{s}\right)-\left[2 b z-b k t(1+\beta)^{2}-k^{2}\left(1+\beta^{2}\right)\right]\left(e_{m}+e_{s}\right)\right\},
\end{aligned}
$$

the coefficient of the highest order term $z^{3}$ is $16 b^{3}\left(e_{m}+e_{s}\right)$.

To determine the size of $E^{C^{*}}$ and $E^{D^{*}}$, we need to determine the size of $F(z)$ and 0 . The solution of the equation $F(z)=0$ is written by $z_{1}, z_{2}, z_{3}$. Firstly, the coefficient of the highest order term is $16 b^{3}\left(e_{m}+e_{s}\right)>0$; Secondly, we use some special points to judge null points of $F(z)$,

$$
\begin{gathered}
F\left(\frac{k^{2}+2 b k t+b^{2} t^{2}\left(1-\beta^{2}\right)}{2 b}\right) \\
=-b t \beta(1+\beta)\left[k^{2} \beta^{2}+2 b k t \beta(2+\beta)+b^{2} t^{2}\left(1+4 \beta+3 \beta^{2}\right)\right]^{2}\left(a-b c_{m}-b c_{s}-b t e_{m}-b t e_{s}\right) \\
<0, \\
F\left(\frac{k^{2}\left(2+\beta^{2}\right)+2 b k t\left(2+2 \beta+\beta^{2}\right)+b^{2} t^{2}\left(3+4 \beta+\beta^{2}\right)}{4 b}\right) \\
=\frac{1}{4}(1+\beta)[k(1+\beta)+b t(2+\beta)]\left[k^{2} \beta^{2}+2 b k t \beta(2+\beta)+b^{2} t^{2}\left(1+4 \beta+3 \beta^{2}\right)\right]^{2}\left(a-b c_{m}-b c_{s}-b t e_{m}-b t e_{s}\right) \\
>0, \quad F\left(\frac{2 b k t(1+\beta)^{2}+k^{2}\left(1+\beta^{2}\right)+2 b^{2} t^{2}(1+\beta)^{2}}{2 b}\right) \\
=-(k+2 b t)(1+\beta)^{2}\left[k^{2} \beta^{2}+2 b k t \beta(2+\beta)+b^{2} t^{2}\left(1+4 \beta+3 \beta^{2}\right)\right]^{2}\left(a-b c_{m}-b c_{s}-b t e_{m}-b t e_{s}\right) \\
<0,
\end{gathered}
$$




$$
\begin{aligned}
& F(+\infty)=+\infty \text {, according to the mean value theorem we have } \\
& z_{1} \in\left(\frac{k^{2}+2 b k t+b^{2} t^{2}-b^{2} t^{2} \beta^{2}}{2 b}, \frac{k^{2}\left(2+\beta^{2}\right)+2 b k t\left(2+2 \beta+\beta^{2}\right)+b^{2} t^{2}\left(3+4 \beta+\beta^{2}\right)}{4 b}\right) \\
& z_{2} \in\left(\frac{k^{2}\left(2+\beta^{2}\right)+2 b k t\left(2+2 \beta+\beta^{2}\right)+b^{2} t^{2}\left(3+4 \beta+\beta^{2}\right)}{4 b}, \frac{2 b k t(1+\beta)^{2}+k^{2}\left(1+\beta^{2}\right)+2 b^{2} t^{2}(1+\beta)^{2}}{2 b}\right) \\
& z_{3} \in\left(\frac{2 b k t(1+\beta)^{2}+k^{2}\left(1+\beta^{2}\right)+2 b^{2} t^{2}(1+\beta)^{2}}{2 b},+\infty\right) \\
& \text { Lastly, by } z>\frac{2 b k t(1+\beta)^{2}+k^{2}\left(1+\beta^{2}\right)+2 b^{2} t^{2}(1+\beta)^{2}}{2 b} \text {, and the character of } \\
& \text { cubic function, we get that when } \\
& \frac{2 b k t(1+\beta)^{2}+k^{2}\left(1+\beta^{2}\right)+2 b^{2} t^{2}(1+\beta)^{2}}{2 b}<z<z_{3} \\
& F(z)<0 \text {, that is } E^{C^{*}}<E^{D^{*}} \text {; when } z>z_{3}, F(z)>0 \text {, that is } E^{C^{*}}>E^{D^{*}} \text {. } \\
& \text { The proof of Proposition } 5 \\
& \text { 1) By } a-b\left(c_{m}+c_{s}\right)-b t\left(e_{m}+e_{s}\right)>0 \text {, } \\
& z>\frac{2 b k t(1+\beta)^{2}+k^{2}\left(1+\beta^{2}\right)+2 b^{2} t^{2}(1+\beta)^{2}}{2 b}, \\
& r_{s}^{C^{*}}-r_{s}^{D^{*}}=\frac{[k \beta+b t(1+\beta)]\left[a-b\left(c_{m}+c_{s}\right)-b t\left(e_{m}+e_{s}\right)\right]\left[2 b z-(k+b t)^{2}+b^{2} t^{2} \beta^{2}\right]}{\left[2 b z-2 b k t(1+\beta)^{2}-k^{2}\left(1+\beta^{2}\right)-2 b^{2} t^{2}(1+\beta)^{2}\right]\left[4 b z-k^{2}\left(2+\beta^{2}\right)-2 b k t\left(2+2 \beta+\beta^{2}\right)-b^{2} t^{2}\left(3+4 \beta+\beta^{2}\right)\right]}>0 . \\
& \text { Make } N=\frac{[k+b t(1+\beta)]\left(a-b c_{m}-b c_{s}-b t e_{m}-b t e_{s}\right)}{4 b z-k^{2}\left(2+\beta^{2}\right)-2 b k t\left(2+2 \beta+\beta^{2}\right)-b^{2} t^{2}\left(3+4 \beta+\beta^{2}\right)}, \\
& r_{m}^{C^{*}}-N=\frac{[k+b t(1+\beta)]\left[a-b\left(c_{m}+c_{s}\right)-b t\left(e_{m}+e_{s}\right)\right]\left[2 b z-(k+b t)^{2}+b^{2} t^{2} \beta^{2}\right]}{\left[2 b z-2 b k t(1+\beta)^{2}-k^{2}\left(1+\beta^{2}\right)-2 b^{2} t^{2}(1+\beta)^{2}\right]\left[4 b z-k^{2}\left(2+\beta^{2}\right)-2 b k t\left(2+2 \beta+\beta^{2}\right)-b^{2} t^{2}\left(3+4 \beta+\beta^{2}\right)\right]}>0, \\
& \text { that is } r_{m}^{C^{*}}>N \text {, and because } \\
& N-r_{m}^{D^{*}}=\frac{b t \beta\left[a-b\left(c_{m}+c_{s}\right)-b t\left(e_{m}+e_{s}\right)\right]}{4 b z-k^{2}\left(2+\beta^{2}\right)-2 b k t\left(2+2 \beta+\beta^{2}\right)-b^{2} t^{2}\left(3+4 \beta+\beta^{2}\right)} \geq 0, \\
& \text { that is } N \geq r_{m}^{D^{*}} \text {, thus } r_{m}^{C^{*}}>r_{m}^{D^{*}} \text {. } \\
& \pi^{C^{*}}-\pi^{D^{*}}=\frac{z\left[a-b\left(c_{m}+c_{s}\right)-b t\left(e_{m}+e_{s}\right)\right]^{2} h(z)}{2\left[2 b z-2 b k t(1+\beta)^{2}-k^{2}\left(1+\beta^{2}\right)-2 b^{2} t^{2}(1+\beta)^{2}\right]\left[4 b z-k^{2}\left(2+\beta^{2}\right)-2 b k t\left(2+2 \beta+\beta^{2}\right)-b^{2} t^{2}\left(3+4 \beta+\beta^{2}\right)\right]^{2}}, \\
& h(z)=4 b^{2} z^{2}-z\left[4 b k^{2}+8 b^{2} k t+2 b^{3} t^{2}\left(2-3 \beta^{2}\right)\right]-b^{4} t^{4}(1+\beta)^{2}\left(-1+2 \beta+\beta^{2}\right) \\
& -b^{2} k^{2} t^{2}\left(-6+3 \beta^{2}+\beta^{4}\right)-2 b^{3} k t^{3}\left(-2+3 \beta^{2}+2 \beta^{3}+\beta^{4}\right)+k^{4}+4 b k^{3} t,
\end{aligned}
$$


to determine the size of $\pi^{C^{*}}$ and $\pi^{D^{*}}$, we need determine the size of $h(z)$ and 0 . Owing to $z>\frac{2 b k t(1+\beta)^{2}+k^{2}\left(1+\beta^{2}\right)+2 b^{2} t^{2}(1+\beta)^{2}}{2 b}, 0 \leq \beta \leq 1$, $k, b, t>0$, we have $h^{\prime}(z)=b\left[8 b z-4(k+b t)^{2}+6 b^{2} t^{2} \beta^{2}\right]>0$, that means

$h(z)$ is monotone increasing about $z$, so

$$
\begin{gathered}
h(z)>h\left(\frac{2 b k t(1+\beta)^{2}+k^{2}\left(1+\beta^{2}\right)+2 b^{2} t^{2}(1+\beta)^{2}}{2 b}\right)=\left[k^{2} \beta^{2}+2 b k t \beta(2+\beta)+b^{2} t^{2}\left(1+4 \beta+3 \beta^{2}\right)\right]^{2}>0, \\
\text { thus } \pi^{C^{*}}>\pi^{D^{*}} . \\
2) \quad-\left[a-b\left(c_{m}+c_{s}\right)-b t\left(e_{m}+e_{s}\right)\right] y(z)
\end{gathered}
$$

where

$$
\begin{aligned}
y(z)= & -2(k+b t)(k \beta+b t(1+\beta))(k \beta+b t(2+\beta)) \\
& \times\left(2 b k t(1+\beta)^{2}+k^{2}\left(1+\beta^{2}\right)+2 b\left(-z+b t^{2}(1+\beta)^{2}\right)\right) \\
& \times\left(k^{2}+2 b k t+b\left(-2 z-b t^{2}\left(-1+\beta^{2}\right)\right)\right)-2 b^{2} t^{2} \beta(k \beta+b t(1+\beta)) \\
& \times\left(2 b k t(1+\beta)^{2}+k^{2}\left(1+\beta^{2}\right)+2 b\left(-z+b t^{2}(1+\beta)^{2}\right)\right) \\
& \times\left(k^{2}\left(2+\beta^{2}\right)+2 b k t\left(2+2 \beta+\beta^{2}\right)+b\left(-4 z+b t^{2}\left(3+4 \beta+\beta^{2}\right)\right)\right) \\
& -(k \beta+b t(1+\beta))\left(2 k^{2} \beta+4 b k t(1+\beta)+4 b^{2} t^{2}(1+\beta)\right) \\
& \times\left(k^{2}+2 b k t+b\left(-2 z-b t^{2}\left(-1+\beta^{2}\right)\right)\right) \\
& \times\left(k^{2}\left(2+\beta^{2}\right)+2 b k t\left(2+2 \beta+\beta^{2}\right)+b\left(-4 z+b t^{2}\left(3+4 \beta+\beta^{2}\right)\right)\right) \\
& +(k+b t)\left(2 b k t(1+\beta)^{2}+k^{2}\left(1+\beta^{2}\right)+2 b\left(-z+b t^{2}(1+\beta)^{2}\right)\right) \\
& \times\left(k^{2}+2 b k t+b\left(-2 z-b t^{2}\left(-1+\beta^{2}\right)\right)\right) \\
& \times\left(k^{2}\left(2+\beta^{2}\right)+2 b k t\left(2+2 \beta+\beta^{2}\right)+b\left(-4 z+b t^{2}\left(3+4 \beta+\beta^{2}\right)\right)\right),
\end{aligned}
$$

to determine the size of $\frac{\partial\left(r_{s}^{C^{*}}-r_{s}^{D^{*}}\right)}{\partial \beta}$ and 0 , we need determine the size of $y(z)$ and 0 . Due to $y^{\prime \prime \prime}(z)=-96 b^{3}(k+b t)<0$, that means $y^{\prime \prime}(z)$ is monotone decreasing about $z$. Because $z>\frac{2 b k t(1+\beta)^{2}+k^{2}\left(1+\beta^{2}\right)+2 b^{2} t^{2}(1+\beta)^{2}}{2 b}$, $0 \leq \beta \leq 1, k, b, t>0$, we have

$$
\begin{aligned}
y^{\prime \prime}(z) & <y^{\prime \prime}\left(\frac{2 b k t(1+\beta)^{2}+k^{2}\left(1+\beta^{2}\right)+2 b^{2} t^{2}(1+\beta)^{2}}{2 b}\right) \\
& =-8 b^{2}\left[9 k^{3} \beta^{2}+3 b k^{2} t \beta(10+9 \beta)+b^{3} t^{3}\left(15+38 \beta+23 \beta^{2}\right)+b^{2} k t^{2}\left(15+60 \beta+41 \beta^{2}\right)\right] \\
& <0,
\end{aligned}
$$


that means $y^{\prime}(z)$ is monotone decreasing about $z$, moreover we can get

$$
\begin{aligned}
y^{\prime}(z)< & y^{\prime}\left(\frac{2 b k t(1+\beta)^{2}+k^{2}\left(1+\beta^{2}\right)+2 b^{2} t^{2}(1+\beta)^{2}}{2 b}\right) \\
= & -2 b\left[9 k^{5} \beta^{4}+b k^{4} t \beta^{3}(64+45 \beta)+b^{5} t^{5}(1+\beta)^{2}\left(17+70 \beta+57 \beta^{2}\right)\right. \\
& +2 b^{2} k^{3} t^{2} \beta^{2}\left(69+128 \beta+59 \beta^{2}\right)+2 b^{3} k^{2} t^{3} \beta\left(48+207 \beta+244 \beta^{2}+87 \beta^{3}\right) \\
& \left.+b^{4} k t^{4}\left(17+192 \beta+490 \beta^{2}+464 \beta^{3}+149 \beta^{4}\right)\right] \\
< & 0,
\end{aligned}
$$

that means $y(z)$ is monotone decreasing about $z$, so

$$
\begin{aligned}
y(z)< & y\left(\frac{2 b k t(1+\beta)^{2}+k^{2}\left(1+\beta^{2}\right)+2 b^{2} t^{2}(1+\beta)^{2}}{2 b}\right) \\
= & -2[k \beta+b t(1+\beta)]\left[k^{2} \beta+2 b k t(1+\beta)+2 b^{2} t^{2}(1+\beta)\right] \\
& \times\left[k^{2} \beta^{2}+2 b k t \beta(2+\beta)+b^{2} t^{2}\left(1+4 \beta+3 \beta^{2}\right)\right]^{2} \\
< & 0
\end{aligned}
$$

thus $\frac{\partial\left(r_{s}^{C^{*}}-r_{s}^{D^{*}}\right)}{\partial \beta}>0$

$\frac{\partial\left(r_{m}^{C^{*}}-r_{m}^{D^{*}}\right)}{\partial \beta}=\frac{-\left[a-b\left(c_{m}+c_{s}\right)-b t\left(e_{m}+e_{s}\right)\right] x(z)}{\left[2 b z-2 b t(k+b t)(1+\beta)^{2}-k^{2}\left(1+\beta^{2}\right)\right]^{2}\left[4 b z-k^{2}\left(2+\beta^{2}\right)-2 b k t\left(2+2 \beta+\beta^{2}\right)-b^{2} t^{2}\left(3+4 \beta+\beta^{2}\right)\right]^{2}}$

where

$$
\begin{aligned}
x(z)= & 2(k+b t)^{2}[k \beta+b t(2+\beta)]\left[2 b z-2 b t(k+b t)(1+\beta)^{2}-k^{2}\left(1+\beta^{2}\right)\right]^{2} \\
& -\left\{2 k^{3} \beta+2 b^{3} t^{3}(1+\beta)^{2}+b k^{2} t\left(3+6 \beta+\beta^{2}\right)+2 b^{2} t\left[z+k t\left(3+4 \beta+\beta^{2}\right)\right]\right\} \\
& \times\left[4 b z-k^{2}\left(2+\beta^{2}\right)-2 b k t\left(2+2 \beta+\beta^{2}\right)-b^{2} t^{2}\left(3+4 \beta+\beta^{2}\right)\right]^{2},
\end{aligned}
$$

to determine the size of $\frac{\partial\left(r_{m}^{C^{*}}-r_{m}^{D^{*}}\right)}{\partial \beta}$ and 0 , we need to determine the size of $x(z)$ and 0 . Since $x^{\prime \prime \prime}(z)=-192 b^{4} t<0$, so $x^{\prime \prime}(z)$ is monotone decreasing about $z$. By $0 \leq \beta \leq 1, k, b, t>0, \quad z>\frac{2 b k t(1+\beta)^{2}+k^{2}\left(1+\beta^{2}\right)+2 b^{2} t^{2}(1+\beta)^{2}}{2 b}$, we have

$$
\begin{aligned}
x^{\prime \prime}(z) & <x^{\prime \prime}\left(\frac{2 b k t(1+\beta)^{2}+k^{2}\left(1+\beta^{2}\right)+2 b^{2} t^{2}(1+\beta)^{2}}{2 b}\right) \\
& =-16 b^{2}\left[3 k^{3} \beta+3 b k^{2} t\left(2+3 \beta+2 \beta^{2}\right)+b^{2} k t^{2}\left(12+29 \beta+12 \beta^{2}\right)+b^{3} t^{3}\left(8+23 \beta+14 \beta^{2}\right)\right] \\
& <0
\end{aligned}
$$

that means $x^{\prime}(z)$ is monotone decreasing about $z$, so 


$$
\begin{aligned}
& x^{\prime}(z)<x^{\prime}\left(\frac{2 b k t(1+\beta)^{2}+k^{2}\left(1+\beta^{2}\right)+2 b^{2} t^{2}(1+\beta)^{2}}{2 b}\right) \\
& =-2 b\left[k^{2} \beta^{2}+2 b k t \beta(2+\beta)+b^{2} t^{2}\left(1+4 \beta+3 \beta^{2}\right)\right] \\
& \times\left[8 k^{3} \beta+b k^{2} t(4+3 \beta)^{2}+2 b^{2} k t^{2}\left(16+26 \beta+9 \beta^{2}\right)+b^{3} t^{3}\left(17+36 \beta+19 \beta^{2}\right)\right] \\
& <0 \text {, } \\
& \text { that means } x(z) \text { is monotone decreasing about } z \text {, so } \\
& x(z)<x\left(\frac{2 b k t(1+\beta)^{2}+k^{2}\left(1+\beta^{2}\right)+2 b^{2} t^{2}(1+\beta)^{2}}{2 b}\right) \\
& =-2\left[k^{3} \beta+2 b^{3} t^{3}(1+\beta)^{2}+b k^{2} t\left(2+3 \beta+\beta^{2}\right)+2 b^{2} k t^{2}\left(2+3 \beta+\beta^{2}\right)\right] \\
& \times\left[k^{2} \beta^{2}+2 b k t \beta(2+\beta)+b^{2} t^{2}\left(1+4 \beta+3 \beta^{2}\right)\right]^{2} \\
& <0 \\
& \text { thus we can get } \frac{\partial\left(r_{m}^{C^{*}}-r_{m}^{D^{*}}\right)}{\partial \beta}>0 \text {. } \\
& \frac{\partial\left(\pi^{C^{*}}-\pi^{D^{*}}\right)}{\partial \beta}=\frac{-z\left[a-b\left(c_{m}+c_{s}\right)-b t\left(e_{m}+e_{s}\right)\right]^{2} r(z)}{2\left[2 b z-2 b t(k+b t)(1+\beta)^{2}-k^{2}\left(1+\beta^{2}\right)\right]^{2}\left[4 b z-k^{2}\left(2+\beta^{2}\right)-2 b k t\left(2+2 \beta+\beta^{2}\right)-b^{2} t^{2}\left(3+4 \beta+\beta^{2}\right)\right]^{3}}, \\
& r(z)=\left[2 k^{2} \beta+4 b k t(1+\beta)+4 b^{2} t^{2}(1+\beta)\right] \\
& \times\left[4 b z-k^{2}\left(2+\beta^{2}\right)-2 b k t\left(2+2 \beta+\beta^{2}\right)-b^{2} t^{2}\left(3+4 \beta+\beta^{2}\right)\right]^{3} \\
& -2(k+b t)[k \beta+b t(2+\beta)]\left[k^{2}\left(4+\beta^{2}\right)+2 b k t\left(4+2 \beta+\beta^{2}\right)\right. \\
& \left.+b^{2} t^{2}\left(5+4 \beta+\beta^{2}\right)-8 b z\right]\left[2 b z-2 b t(k+b t)(1+\beta)^{2}-k^{2}\left(1+\beta^{2}\right)\right]^{2}, \\
& r^{\prime \prime \prime}(z)=-384 b^{3}\left[k^{2} \beta+2 b k t(1+\beta)+b^{2} t^{2}(2+3 \beta)\right]<0, \\
& z>\frac{2 b k t(1+\beta)^{2}+k^{2}\left(1+\beta^{2}\right)+2 b^{2} t^{2}(1+\beta)^{2}}{2 b}, \\
& r^{\prime \prime}(z)<r^{\prime \prime}\left(\frac{2 b k t(1+\beta)^{2}+k^{2}\left(1+\beta^{2}\right)+2 b^{2} t^{2}(1+\beta)^{2}}{2 b}\right) \\
& =-16 b^{2}\left[9 k^{4} \beta^{3}+18 b k^{3} t \beta^{2}(3+2 \beta)+b^{2} k^{2} t^{2} \beta\left(81+162 \beta+86 \beta^{2}\right)\right. \\
& \left.+2 b^{3} k t^{3}\left(9+81 \beta+125 \beta^{2}+50 \beta^{3}\right)+b^{4} t^{4}\left(18+93 \beta+142 \beta^{2}+65 \beta^{3}\right)\right] \\
& <0 \text {, }
\end{aligned}
$$


that means $r^{\prime}(z)$ is monotone decreasing about $Z$, so

$$
\begin{aligned}
r^{\prime}(z)< & r^{\prime}\left(\frac{2 b k t(1+\beta)^{2}+k^{2}\left(1+\beta^{2}\right)+2 b^{2} t^{2}(1+\beta)^{2}}{2 b}\right) \\
= & -24 b\left[k^{2} \beta+2 b k t(1+\beta)+2 b^{2} t^{2}(1+\beta)\right] \\
& \times\left[k^{2} \beta^{2}+2 b k t \beta(2+\beta)+b^{2} t^{2}\left(1+4 \beta+3 \beta^{2}\right)\right]^{2} \\
< & 0,
\end{aligned}
$$

that means $r(z)$ is monotone decreasing about $Z$, so

$$
\begin{aligned}
r(z)< & r\left(\frac{2 b k t(1+\beta)^{2}+k^{2}\left(1+\beta^{2}\right)+2 b^{2} t^{2}(1+\beta)^{2}}{2 b}\right) \\
= & -2\left[k^{2} \beta+2 b k t(1+\beta)+2 b^{2} t^{2}(1+\beta)\right] \\
& \times\left[k^{2} \beta^{2}+2 b k t \beta(2+\beta)+b^{2} t^{2}\left(1+4 \beta+3 \beta^{2}\right)\right]^{3} \\
< & 0,
\end{aligned}
$$

thus $\frac{\partial\left(\pi^{C^{*}}-\pi^{D^{*}}\right)}{\partial \beta}>0$.

3)

$\frac{\partial\left(r_{s}^{C^{*}}-r_{s}^{D^{*}}\right)}{\partial k}=\frac{-\left[a-b\left(c_{m}+c_{s}\right)-b t\left(e_{m}+e_{s}\right)\right] Y(z)}{\left[2 b z-2 b t(k+b t)(1+\beta)^{2}-k^{2}\left(1+\beta^{2}\right)\right]^{2}\left[4 b z-k^{2}\left(2+\beta^{2}\right)-2 b k t\left(2+2 \beta+\beta^{2}\right)-b^{2} t^{2}\left(3+4 \beta+\beta^{2}\right)\right]^{2}}$,

where

$$
\begin{aligned}
Y(z)= & \left(-(k \beta+b t(1+\beta))\left(2 k\left(2+\beta^{2}\right)+2 b t\left(2+2 \beta+\beta^{2}\right)\right)\right. \\
& \times\left(2 b k t(1+\beta)^{2}+k^{2}\left(1+\beta^{2}\right)+2 b\left(-z+b t^{2}(1+\beta)^{2}\right)\right) \\
& \times\left(k^{2}+2 b k t+b\left(-2 z-b t^{2}\left(-1+\beta^{2}\right)\right)\right)+2(k+b t)(k \beta+b t(1+\beta)) \\
& \times\left(2 b k t(1+\beta)^{2}+k^{2}\left(1+\beta^{2}\right)+2 b\left(-z+b t^{2}(1+\beta)^{2}\right)\right) \\
& \times\left(k^{2}\left(2+\beta^{2}\right)+2 b k t\left(2+2 \beta+\beta^{2}\right)+b\left(-4 z+b t^{2}\left(3+4 \beta+\beta^{2}\right)\right)\right) \\
& -(k \beta+b t(1+\beta))\left(2 b t(1+\beta)^{2}+2 k\left(1+\beta^{2}\right)\right) \\
& \times\left(k^{2}+2 b k t+b\left(-2 z-b t^{2}\left(-1+\beta^{2}\right)\right)\right) \\
& \times\left(k^{2}\left(2+\beta^{2}\right)+2 b k t\left(2+2 \beta+\beta^{2}\right)+b\left(-4 z+b t^{2}\left(3+4 \beta+\beta^{2}\right)\right)\right) \\
& +\beta\left(2 b k t(1+\beta)^{2}+k^{2}\left(1+\beta^{2}\right)+2 b\left(-z+b t^{2}(1+\beta)^{2}\right)\right) \\
& \times\left(k^{2}+2 b k t+b\left(-2 z-b t^{2}\left(-1+\beta^{2}\right)\right)\right) \\
& \left.\times\left(k^{2}\left(2+\beta^{2}\right)+2 b k t\left(2+2 \beta+\beta^{2}\right)+b\left(-4 z+b t^{2}\left(3+4 \beta+\beta^{2}\right)\right)\right)\right),
\end{aligned}
$$

to determine the size of $\frac{\partial\left(r_{s}^{C^{*}}-r_{s}^{D^{*}}\right)}{\partial k}$ and 0 , we need to determine the size of 
$Y(z)$ and 0 . Owing to $0 \leq \beta \leq 1, k, b, t>0$, then $Y^{\prime \prime \prime}(z)=-96 b^{3} \beta<0$, that means $Y^{\prime \prime}(z)$ is monotone decreasing about $z$. By

$$
\begin{aligned}
z & >\frac{2 b k t(1+\beta)^{2}+k^{2}\left(1+\beta^{2}\right)+2 b^{2} t^{2}(1+\beta)^{2}}{2 b}, \\
Y^{\prime \prime}(z)<Y^{\prime \prime} & \left(\frac{2 b k t(1+\beta)^{2}+k^{2}\left(1+\beta^{2}\right)+2 b^{2} t^{2}(1+\beta)^{2}}{2 b}\right)
\end{aligned}
$$

we have

$$
\begin{aligned}
= & -8 b^{2}\left[k^{2} \beta\left(4+9 \beta^{2}\right)+2 b k t\left(2+4 \beta+15 \beta^{2}+9 \beta^{3}\right),\right. \text { that means } \\
& \left.+b^{2} t^{2}\left(4+19 \beta+30 \beta^{2}+15 \beta^{3}\right)\right] \\
< & 0
\end{aligned}
$$

$Y^{\prime}(z)$ is monotone decreasing about $z$, so

$$
\begin{aligned}
Y^{\prime}(z)< & Y^{\prime}\left(\frac{2 b k t(1+\beta)^{2}+k^{2}\left(1+\beta^{2}\right)+2 b^{2} t^{2}(1+\beta)^{2}}{2 b}\right) \\
= & -2 b\left[k^{4} \beta^{3}\left(8+9 \beta^{2}\right)+4 b k^{3} t \beta^{2}\left(10+8 \beta+16 \beta^{2}+9 \beta^{3}\right)\right. \\
& +b^{4} t^{4}(1+\beta)^{2}\left(8+41 \beta+62 \beta^{2}+33 \beta^{3}\right) \\
& +2 b^{2} k^{2} t^{2} \beta\left(20+60 \beta+101 \beta^{2}+96 \beta^{3}+37 \beta^{4}\right) \\
& \left.+4 b^{3} k t^{3}\left(2+20 \beta+58 \beta^{2}+85 \beta^{3}+64 \beta^{4}+19 \beta^{5}\right)\right] \\
< & 0,
\end{aligned}
$$

that means $Y(z)$ is monotone decreasing about $z$, so

$$
\begin{aligned}
Y(z)< & Y\left(\frac{2 b k t(1+\beta)^{2}+k^{2}\left(1+\beta^{2}\right)+2 b^{2} t^{2}(1+\beta)^{2}}{2 b}\right) \\
= & -2[k \beta+b t(1+\beta)]\left[b t(1+\beta)^{2}+k\left(1+\beta^{2}\right)\right] \\
& \times\left[k^{2} \beta^{2}+2 b k t \beta(2+\beta)+b^{2} t^{2}\left(1+4 \beta+3 \beta^{2}\right)\right]^{2} \\
< & 0,
\end{aligned}
$$

thus $\frac{\partial\left(r_{s}^{C^{*}}-r_{s}^{D^{*}}\right)}{\partial k}>0$.

$\frac{\partial\left(r_{m}^{C^{*}}-r_{m}^{D^{*}}\right)}{\partial k}=\frac{-\left[a-b\left(c_{m}+c_{s}\right)-b t\left(e_{m}+e_{s}\right)\right] X(z)}{\left[2 b z-2 b t(k+b t)(1+\beta)^{2}-k^{2}\left(1+\beta^{2}\right)\right]^{2}\left[4 b z-k^{2}\left(2+\beta^{2}\right)-2 b k t\left(2+2 \beta+\beta^{2}\right)-b^{2} t^{2}\left(3+4 \beta+\beta^{2}\right)\right]^{2}}$,

where

$$
\begin{aligned}
X(z)= & \left\{k^{2}\left(2+\beta^{2}\right)+2 b k t\left(2+\beta^{2}\right)+b\left[4 z+b t^{2}\left(1+\beta^{2}\right)\right]\right\} \\
& \times\left[2 b z-2 b t(k+b t)(1+\beta)^{2}-k^{2}\left(1+\beta^{2}\right)\right]^{2} \\
& -\left\{k^{2}\left(1+\beta^{2}\right)+2 b k t\left(1+\beta+\beta^{2}+\beta^{3}\right)+2 b\left[z+b t^{2} \beta(1+\beta)^{2}\right]\right\} \\
& \times\left[4 b z-k^{2}\left(2+\beta^{2}\right)-2 b k t\left(2+2 \beta+\beta^{2}\right)-b^{2} t^{2}\left(3+4 \beta+\beta^{2}\right)\right]^{2},
\end{aligned}
$$




$$
\begin{aligned}
& \text { to determine the size of } \frac{\partial\left(r_{m}^{C^{*}}-r_{m}^{D^{*}}\right)}{\partial k} \text { and } 0 \text {, we need to determine the size of } \\
& X(z) \text { and } 0 \text {. Due to } 0 \leq \beta \leq 1, k, b, t>0 \text {, we have } X^{\prime \prime \prime}(z)=-96 b^{3}<0 \text {, that } \\
& \text { means } X^{\prime \prime}(z) \text { is monotone decreasing about } z \text {. Since } \\
& z>\frac{2 b k t(1+\beta)^{2}+k^{2}\left(1+\beta^{2}\right)+2 b^{2} t^{2}(1+\beta)^{2}}{2 b}, \\
& X^{\prime \prime}(z)<X^{\prime \prime}\left(\frac{2 b k t(1+\beta)^{2}+k^{2}\left(1+\beta^{2}\right)+2 b^{2} t^{2}(1+\beta)^{2}}{2 b}\right) \\
& =-8 b^{2}\left[k^{2}\left(4+9 \beta^{2}\right)+2 b k t\left(4+16 \beta+9 \beta^{2}+4 \beta^{3}\right),\right. \\
& \left.+b^{2} t^{2}\left(7+32 \beta+31 \beta^{2}+8 \beta^{3}\right)\right] \\
& <0
\end{aligned}
$$

that means $X^{\prime}(z)$ is monotone decreasing about $z$, so

$$
\begin{aligned}
X^{\prime}(z)< & X^{\prime}\left(\frac{2 b k t(1+\beta)^{2}+k^{2}\left(1+\beta^{2}\right)+2 b^{2} t^{2}(1+\beta)^{2}}{2 b}\right) \\
= & -2 b\left[k^{4} \beta^{2}\left(8+9 \beta^{2}\right)+b^{4} t^{4}(1+\beta)^{2}\left(9+46 \beta+65 \beta^{2}+24 \beta^{3}\right)\right. \\
& +4 b k^{3} t \beta\left(8+8 \beta+16 \beta^{2}+9 \beta^{3}+2 \beta^{4}\right) \\
& +4 b^{3} k t^{3}\left(4+32 \beta+77 \beta^{2}+82 \beta^{3}+43 \beta^{4}+10 \beta^{5}\right) \\
& \left.+2 b^{2} k^{2} t^{2}\left(4+48 \beta+93 \beta^{2}+96 \beta^{3}+61 \beta^{4}+12 \beta^{5}\right)\right] \\
< & 0,
\end{aligned}
$$

that means $X(z)$ is monotone decreasing about $z$, so

$$
\begin{aligned}
& \qquad(z)<X\left(\frac{2 b k t(1+\beta)^{2}+k^{2}\left(1+\beta^{2}\right)+2 b^{2} t^{2}(1+\beta)^{2}}{2 b}\right) \\
& =-2\left[k^{2} \beta^{2}+2 b k t \beta(2+\beta)+b^{2} t^{2}\left(1+4 \beta+3 \beta^{2}\right)\right]^{2} \\
& \quad \times\left[b^{2} t^{2}(1+\beta)^{3}+k^{2}\left(1+\beta^{2}\right)+b k t\left(2+3 \beta+2 \beta^{2}+\beta^{3}\right)\right] \\
& <0, \\
& \text { thus } \frac{\partial\left(r_{m}^{C^{*}}-r_{m}^{D^{*}}\right)}{\partial k}>0 .
\end{aligned}
$$$$
\frac{\partial\left(\pi^{C^{*}}-\pi^{D^{*}}\right)}{\partial k}=\frac{-z\left[a-b\left(c_{m}+c_{s}\right)-b t\left(e_{m}+e_{s}\right)\right]^{2} R(z)}{2\left[2 b z-2 b t(k+b t)(1+\beta)^{2}-k^{2}\left(1+\beta^{2}\right)\right]^{2}\left[4 b z-k^{2}\left(2+\beta^{2}\right)-2 b k t\left(2+2 \beta+\beta^{2}\right)-b^{2} t^{2}\left(3+4 \beta+\beta^{2}\right)\right]^{3}},
$$

where

$$
\begin{aligned}
R(z)= & 2\left(-2\left(k\left(2+\beta^{2}\right)+b t\left(2+2 \beta+\beta^{2}\right)\right)\left(k^{2}\left(3+\beta^{2}\right)+2 b k t\left(3+2 \beta+\beta^{2}\right)\right.\right. \\
& \left.+b\left(-6 z+b t^{2}(2+\beta)^{2}\right)\right)+\left(k\left(3+\beta^{2}\right)+b t\left(3+2 \beta+\beta^{2}\right)\right)
\end{aligned}
$$




$$
\begin{aligned}
& \left.\times\left(k^{2}\left(2+\beta^{2}\right)+2 b k t\left(2+2 \beta+\beta^{2}\right)+b\left(-4 z+b t^{2}\left(3+4 \beta+\beta^{2}\right)\right)\right)\right) \\
& \times\left[2 b z-2 b t(k+b t)(1+\beta)^{2}-k^{2}\left(1+\beta^{2}\right)\right]^{2}-2\left[b t(1+\beta)^{2}+k\left(1+\beta^{2}\right)\right] \\
& \times\left[4 b z-k^{2}\left(2+\beta^{2}\right)-2 b k t\left(2+2 \beta+\beta^{2}\right)-b^{2} t^{2}\left(3+4 \beta+\beta^{2}\right)\right]^{3},
\end{aligned}
$$

to determine the size of $\frac{\partial\left(\pi^{C^{*}}-\pi^{D^{*}}\right)}{\partial k}$ and 0 , we need to determine the size of $R(z)$ and 0 . Since $0 \leq \beta \leq 1, k, b, t>0$, then

$$
R^{\prime \prime \prime}(z)=-192 b^{3}\left[k+2 k \beta^{2}+b t\left(1+4 \beta+2 \beta^{2}\right)\right]<0,
$$

that means $R^{\prime \prime}(z)$ is monotone decreasing about $z$. By

$$
z>\frac{2 b k t(1+\beta)^{2}+k^{2}\left(1+\beta^{2}\right)+2 b^{2} t^{2}(1+\beta)^{2}}{2 b},
$$

we have

$$
\begin{aligned}
R^{\prime \prime}(z)< & R^{\prime \prime}\left(\frac{2 b k t(1+\beta)^{2}+k^{2}\left(1+\beta^{2}\right)+2 b^{2} t^{2}(1+\beta)^{2}}{2 b}\right) \\
= & -16 b^{2}\left[k^{3} \beta^{2}\left(7+9 \beta^{2}\right)+b k^{2} t \beta\left(28+21 \beta+54 \beta^{2}+27 \beta^{3}\right)\right. \\
& +b^{3} t^{3}\left(7+46 \beta+106 \beta^{2}+94 \beta^{3}+29 \beta^{4}\right) \\
& \left.+b^{2} k t^{2}\left(7+56 \beta+120 \beta^{2}+108 \beta^{3}+47 \beta^{4}\right)\right] \\
< & 0,
\end{aligned}
$$

that means $R^{\prime}(z)$ is monotone decreasing about $z$, so

$$
\begin{aligned}
R^{\prime}(z) & <R^{\prime}\left(\frac{2 b k t(1+\beta)^{2}+k^{2}\left(1+\beta^{2}\right)+2 b^{2} t^{2}(1+\beta)^{2}}{2 b}\right) \\
& =-24 b\left[b t(1+\beta)^{2}+k\left(1+\beta^{2}\right)\right]\left[k^{2} \beta^{2}+2 b k t \beta(2+\beta)+b^{2} t^{2}\left(1+4 \beta+3 \beta^{2}\right)\right]^{2} \\
& <0,
\end{aligned}
$$

that means $R(z)$ is monotone decreasing about $z$, so

$$
\begin{aligned}
& R(z)<R\left(\frac{2 b k t(1+\beta)^{2}+k^{2}\left(1+\beta^{2}\right)+2 b^{2} t^{2}(1+\beta)^{2}}{2 b}\right) \\
& =-2\left[b t(1+\beta)^{2}+k\left(1+\beta^{2}\right)\right]\left[k^{2} \beta^{2}+2 b k t \beta(2+\beta)+b^{2} t^{2}\left(1+4 \beta+3 \beta^{2}\right)\right]^{3} \\
& <0 \text {, } \\
& \text { thus } \frac{\partial\left(\pi^{C^{*}}-\pi^{D^{*}}\right)}{\partial k}>0 \text {. }
\end{aligned}
$$

\section{The proof of Proposition 6}

1) Due to $0<\tau<1, \pi^{C^{*}}>\pi^{D^{*}}>\pi_{s}^{D^{*}}>\pi_{m}^{D^{*}}$, it is clear that $\theta^{*}>0$. Because $\pi^{C^{*}}-\pi_{m}^{D^{*}}>\pi^{C^{*}}-\pi^{D^{*}}>(1-\tau)\left(\pi^{C^{*}}-\pi^{D^{*}}\right)$, so $\pi^{C^{*}}>(1-\tau)\left(\pi^{C^{*}}-\pi^{D^{*}}\right)+\pi_{m}^{D^{*}}$, thereby $\theta^{*}<1$. 
We know $\pi_{s}^{B^{*}}=\left(1-\theta^{*}\right) \pi^{C^{*}}=\tau\left(\pi^{C^{*}}-\pi^{D^{*}}\right)+\pi_{s}^{D^{*}}$, because of $0<\tau<1$, and $\pi^{C^{*}}>\pi^{D^{*}}$, then we get $\pi_{s}^{B^{*}}>\pi_{s}^{D^{*}}$. Similarly,

$$
\pi_{m}^{B^{*}}=\theta^{*} \pi^{C^{*}}=(1-\tau)\left(\pi^{C^{*}}-\pi^{D^{*}}\right)+\pi_{m}^{D^{*}}>\pi_{m}^{D^{*}} .
$$

2) Owing to $\pi_{s}^{B^{*}}=\left(1-\theta^{*}\right) \pi^{C^{*}}=\tau\left(\pi^{C^{*}}-\pi^{D^{*}}\right)+\pi_{s}^{D^{*}}$, then

$$
\frac{\partial \pi_{s}^{B^{*}}}{\partial \beta}=\tau \frac{\partial\left(\pi^{C^{*}}-\pi^{D^{*}}\right)}{\partial \beta}+\frac{\partial \pi_{s}^{D^{*}}}{\partial \beta} .
$$

By Proposition 3 and Proposition 5, we get $\frac{\partial \pi_{s}^{B^{*}}}{\partial \beta}>0$. Similarly,

$$
\pi_{m}^{B^{*}}=\theta^{*} \pi^{C^{*}}=(1-\tau)\left(\pi^{C^{*}}-\pi^{D^{*}}\right)+\pi_{m}^{D^{*}},
$$

then

$$
\frac{\partial \pi_{m}^{B^{*}}}{\partial \beta}=(1-\tau) \frac{\partial\left(\pi^{C^{*}}-\pi^{D^{*}}\right)}{\partial \beta}+\frac{\partial \pi_{m}^{D^{*}}}{\partial \beta}>0 .
$$

Since $\pi_{s}^{B^{*}}-\pi_{s}^{D^{*}}=\tau\left(\pi^{C^{*}}-\pi^{D^{*}}\right)$, so $\frac{\partial\left(\pi_{s}^{B^{*}}-\pi_{s}^{D^{*}}\right)}{\partial \beta}=\tau \frac{\partial\left(\pi^{C^{*}}-\pi^{D^{*}}\right)}{\partial \beta}$. By Proposition 5, we get $\frac{\partial\left(\pi_{s}^{B^{*}}-\pi_{s}^{D^{*}}\right)}{\partial \beta}>0$. Similarly, because of

$$
\pi_{m}^{B^{*}}-\pi_{m}^{D^{*}}=(1-\tau)\left(\pi^{C^{*}}-\pi^{D^{*}}\right),
$$

we have $\frac{\partial\left(\pi_{m}^{B^{*}}-\pi_{m}^{D^{*}}\right)}{\partial \beta}=(1-\tau) \frac{\partial\left(\pi^{C^{*}}-\pi^{D^{*}}\right)}{\partial \beta}>0$.

3) Since $\frac{\partial \pi_{s}^{B^{*}}}{\partial k}=\tau \frac{\partial\left(\pi^{C^{*}}-\pi^{D^{*}}\right)}{\partial k}+\frac{\partial \pi_{s}^{D^{*}}}{\partial k}$, and by Proposition 3 and Proposition 5, we get $\frac{\partial \pi_{s}^{B^{*}}}{\partial k}>0$. Similarly, $\frac{\partial \pi_{m}^{B^{*}}}{\partial k}=(1-\tau) \frac{\partial\left(\pi^{C^{*}}-\pi^{D^{*}}\right)}{\partial k}+\frac{\partial \pi_{m}^{D^{*}}}{\partial k}>0$.

Due to $\frac{\partial\left(\pi_{s}^{B^{*}}-\pi_{s}^{D^{*}}\right)}{\partial k}=\tau \frac{\partial\left(\pi^{C^{*}}-\pi^{D^{*}}\right)}{\partial k}$, and by Proposition 3 and Proposition 5, we get $\frac{\partial\left(\pi_{s}^{B^{*}}-\pi_{s}^{D^{*}}\right)}{\partial k}>0$. Similarly,

$$
\frac{\partial\left(\pi_{m}^{B^{*}}-\pi_{m}^{D^{*}}\right)}{\partial k}=(1-\tau) \frac{\partial\left(\pi^{C^{*}}-\pi^{D^{*}}\right)}{\partial k}>0 .
$$

